\title{
LA PÉRDIDA DE CULTIVOS ANCESTRALES Y COSTUMBRES TRADICIONALES EN UN MEDIO RURAL DE LA PROVINCIA DE ALICANTE
}

\author{
José Francisco Climent Brotons \\ Licenciatura de Geografía. Universidad de Alicante (España) \\ Correo electrónico: jfcbaljup@ hotmail.es
}

Recibido: 2 de septiembre de 2011. Devuelto para revisión: 15 de noviembre de 2011. Aceptado: 14 de enero de 2012

\section{RESUMEN}

En el trabajo que he realizado hablo de los tipos de cultivos existentes en Relleu y la manera tradicional que había por esta zona de recolectarlos y de cultivarlos, así de cuantos trabajos que se realizaban antaño y han desaparecido debido a la modernización de la maquinaria existente y a ese proceso de globalización que está afectando en todo el mundo. De entre los cultivos que trato, se pueden diferenciar dos tipos los de secano y los de regadío. En los de secano aparece la almendra y el olivo, así como cuantas variedades existentes en esta zona. El regadío en cambio es más amplio en cuanto a variedades no en cuanto a producción, puesto que como detallo son cultivos para autoconsumo. Por último también menciono las obras que realizaron nuestros antepasados y su legado o palimpsesto que nos ha llegado hasta nuestros días.

Palabras clave: Cultivos, costumbres tradicionales, secano, regadío, Alicante.

\begin{abstract}
In the work that I have realized I speak about the types of existing cultures in Relleu and the traditional way that existed for this zone of gathering and of cultivating them, this way of all the works that were realized long ago and they have disappeared due to the modernization of the existing machinery and this process of globalization that it is affecting in the whole world.

Between the cultures that I treat, two types can be differentiated ; those of dryness and those of irrigation. In the first one, the almond and the olive tree appears, as well as all the existing varieties in this zone. On the other hand, the irrigation is more wide as for varieties not as for production, since I detail they are cultures for self-consumption. Finally, I also mention the works that realized our ancestors and his legacy or palimpsest that has come to us to the present day.
\end{abstract}

Keywords: Crops, Traditional Customs, Dry Land, Irrigated Land, Rural, Alicante.

\section{RESUMO}

No trabalho que fiz falam da cultura tipos existentes Relleu e da maneira tradicional nesta área tiveram que coletar e cultivá-las, e quantos empregos que foram feitas há muito tempo e desapareceram devido à modernização das máquinas existentes e o 
processo de globalização que está afetando a todos. Entre as culturas que o tratamento, podemos distinguir dois tipos de sequeiro e irrigada. Aparece em sequeiro amendoeiras e oliveiras e muitas variedades nesta área. Irrigação é bastante amplo em variedades não na produção, porque, como eu detalho estas culturas para consumo doméstico. Finalmente também mencionar as obras que fizeram nossos antepassados e seu legado ou palimpsesto que tem sobrevivido até hoje.

Palavras-chave: Culturas, costumes tradicionais, terra seca, irrigação, Alicante.

\section{INTRODUCCIÓN}

Relleu se trata de un pueblo situado en la franja prelitoral de la provincia de Alicante, a caballo entre la costa y el interior. Rodeado de montañas como la Grana, Cabezón de Oro o el Aguilar, tiene una topografía abrupta con numerosos barrancos y cerros, un relieve muy irregular muy de acuerdo con el topónimo que en castellano se traduce como relieve. Su base económica es en gran medida la agricultura, a pesar que se esta convirtiendo cada vez más en un pueblo dormitorio, ya que las actividades agrícolas están decayendo, desapareciendo y abandonándose. Además no existen otras alternativas como la industria o los servicios. El turismo en esta zona se podría explotar o dinamizar, con algunas propuestas y actuaciones, como por ejemplo los productos artesanos, la cocina y algunas excursiones guiadas explotando los recursos paisajísticos, arquitectónicos y culturales que tiene el municipio.

En cuanto a la población, ha sufrido un aumento en la última década, en 1995 había 700 habitantes y en la actualidad hay unos pocos más de 1200, según consta en el Padrón Municipal de 2011. Se trata de personas, en su mayoría jubilados y británicos que han adquirido una propiedad aquí, con el fin de vivir en tranquilidad y disfrutando de este clima tan maravilloso que tenemos.

En cuanto a la agricultura, esta actividad comienza a degradarse con bastante rapidez. La ausencia de agricultores jóvenes, no augura un relevo generacional de esta actividad, que por otra parte con los cultivos a los que esta enfocada, no deja rendimiento alguno, es una constante pérdida de capital y por lo tanto es comprensible este abandono.

El cultivo de la zona viene determinado por ser de secano, donde la principal cosecha es la almendra, seguida de la aceituna, en menor medida. Y es que por cada hectárea de olivos, existen alrededor de 20 hectáreas de almendros (cálculo aproximado). Una minoría es la perteneciente a la vid y más aún la siembra que esta muy ligada a la caza, más que a la de producir cosecha.

En cuanto al regadío, el enfoque es el de una producción para el autoconsumo, puesto que el amadorio, es un río muy irregular con una fuerte sequía estival puesto que se trata de un río del arco mediterráneo.

En el primero de los epígrafes describiré, la agricultura de secano, tanto el cultivo de la almendra como el de la aceituna en clara progresión. Después en el siguiente epígrafe detallaré a grandes rasgos, la agricultura de regadío y los aprovechamientos del río Amadorio y para terminar este artículo presentaré una forma de aprovechamiento y reutilización de los restos orgánicos de la almazara de Relleu (planta de compostaje) en 
una apuesta por la agricultura ecológica y el desarrollo sostenible que se esta desarrollando esta entidad.

Además, otro apartado esta dedicado a algunas actividades agrícolas tradicionales que se desarrollaban en la localidad y que están en desuso o en fase de abandono. Así como un breve repaso a otra actividad cada vez menos realizada como es la ganadería, que en las décadas pasadas tuvo una importancia notoria en esta localidad.

Este articulo esta basado en mis experiencias y conocimientos personales como agricultor en el trabajo del campo, apoyado por algunos familiares (todo lo que sé me lo ha enseñado mi padre) y con alguna reflexión o comentario de amigos y profesores que conozco. Los datos más específicos han sido sacados del ayuntamiento (censo y PGOU2006). Además para la elaboración de los apartados del olivo he recurrido a un libro escrito por el consejo oleícola internacional del año 2000, para la redacción de las características de las variedades de la aceituna, así como también he contado con la inestimable ayuda del empresario y propietario de la almazara de Relleu, que me ha proporcionado la información necesaria para la realización de dicho apartado. También la comunidad de regantes por medio de la persona de José Daniel Senabre Soler me ha facilitado información de la superficie de regadío. También he utilizado algunos datos sacados de Internet.

\section{LA AGRICULTURA DE SECANO}

Relleu es un pueblo con una clara dedicación a la agricultura y muy por encima a la agricultura de secano. Tal es así que el reparto es abrumador, de las 7690 hectáreas de que consta el término municipal (según PGOU-2006), 650 corresponden a regadío, lo que supone un $8,33 \%$ de la superficie total del término (según comunidad de regantes, 2011). El resto esta repartido en cultivos de secano y monte, ya que la superficie urbana es inapreciable.

Dentro de los cultivos de secano destaca uno por encima de los demás, este es el almendro. La mayor parte de las fincas dedican su explotación a la almendra, siendo este el único cultivo que se comercializa. Existen múltiples variedades de este fruto seco, que después en el apartado dedicado a él detallaré.

En cuanto al resto de cultivos el siguiente en importancia y relevancia es el olivar. El olivo supone la segunda superficie cultiva en estas tierras, aunque la superficie dedicada a este cultivo ha aumentado considerablemente en los últimos años, debido a varios factores que después señalaré.

Después y ya con muchísima menor importancia se encontrarían una serie de cultivos como la vid y algunos frutales como por ejemplo las higueras, los perales, manzanos, cerezas, granadas, albaricoques, nueces, caquis, nísperos, etc... todos ellos frutos para autoabastecimiento. Un claro ejemplo es la vid, la gran mayoría de los propietarios locales producen su propio vino, con múltiples variedades de uva, dando un color clarete a su producto. Entre algunas de estas variedades se encuentra el valencí tanto en la versión blanco o negro, el geronet, moscatell, marseguera. En estas explotaciones aparte de la vid dedicada al vino, también hay variedades de uva de mesa. pero eso sí, siempre para autoconsumo. 
En los años donde el hambre era bastante destacable, sobretodo después de la guerra y postguerra, algunos cultivos de los anteriormente citados se utilizaban de multitud de formas aparte de maduros, algunos de ellos se aprovechaban después de haber estado un tiempo en los secaderos. Los higos o las pasas son un claro ejemplo de cómo las antiguas civilizaciones sabían aprovechar al máximo los recursos que tenían a su alcance.

Otro cultivo que en su día era aprovechado y que en la actualidad ya no se utiliza prácticamente es la algarroba. Se utilizaba para alimentar a los animales que se utilizaban en la labranza como los mulos o los burros y al ganado. Además su semilla tenía varias utilidades en pastelería, decoración alimentaria y otra utilización era pesar el oro en quilates. En la actualidad este producto esta muy devaluado, su cotización en el campo ronda los 8 ó 9 céntimos de euro el kilo. La mayoría de este cultivo se pierde bajo de los árboles o se recoge para los propios animales domésticos (ganado).

Otro factor en cuanto a los cultivos, es la zona en la que se ubiquen, por ejemplo el algarrobo del que estábamos citando, se sitúa en zonas calientes o templadas, para que cuaje su fruto, con alturas superiores a los 500 metros su fruto no cuaja. Esto quiere decir que estaría el árbol verde, bonito, pero que no produciría fruto alguno debido a las condiciones climáticas y de adaptación de árbol propiamente dicho.

Este sería solo un ejemplo de algo que les sucede a todas las especies bióticas existentes, no todas se adaptan a las diferentes condiciones climáticas y ambientales. Como es obvio pensar, en las zonas elevadas donde el factor altitud es determinante existirán una serie de cultivos diferentes a los de las zonas medias o bajas. Por ejemplo las cerezas y las manzanas necesitan un mayor grado de humedad y menores temperaturas que a alturas o latitudes inferiores no se dan y por lo tanto su fruto no cuaja. Lo mismo pasa en las medias y las bajas alturas o latitudes que dependiendo de su temperatura o humedad, funcionan o no una serie de especies, como por ejemplo el níspero o la higuera. En cambio la vid es un cultivo que se adapta a cualquier terreno solo necesita humedad, en cuanto a su maduración existe una diferencia, en zonas bajas madurara antes que en zonas altas debido a las temperaturas. Esta regla es general para todos los cultivos todo-terrenos, como el olivo y la almendra del que paso a detallar a continuación. Tan solo señalar que para que esto ocurra tiene que haber distintas variedades de almendras y aceitunas.

En este mismo apartado de cultivos de secano uno que esta perdiendo o ha perdido todo protagonismo es el de la siembra y en especial el trigo. Desde que lo introdujeron los fenicios, este cultivo ha servido para la fabricación del pan y aquí en esta zona existían varios molinos impulsados por la fuerza hidráulica que servían para convertir el trigo en harina. En la actualidad, ya no se cultivan bancales con este fin, ahora como mucho se siembra para alimento de animales domésticos, tanto para el ganado como para las aves de corral, bien sea gallinas, pollos o las mismas palomas. También hay otras variedades de siembra como la cebada, la avena, la alfalfa o el maíz (estas últimas de regadío), variedades todas ellas donde el cultivo es algo prácticamente efímero es su mayoría un capricho personal. Todo esto es debido a la poca productividad de este tipo de cultivo y su elevada necesidad de mano de obra puesto que aquí los bancales son estrechos, cortos y donde la maquinaria es muy difícil que consiga trabajar con facilidad. 
En cambio en estos últimos años, la tendencia en cuanto a siembra para no recolectarla ha cambiado un poco, debido en gran parte a dos factores, uno es las ayudas recibidas por la PAC, tanto para aumentar la productividad de la tierra como por las subvenciones que se reciben por realizar este cultivo y el otro factor es que los cotos de caza que existen en este territorio siembran para que las especies cinegéticas puedan alimentarse durante los meses de verano que es cuando la comida es menos abundante. Esta actividad aunque parezca menor es más habitual de lo que se cree, pues aunque estas hectáreas no estas declaradas como tal, son muchas las dedicadas para este fin. La mayor parte de estas hectáreas están sembradas de trigo, cebada, berzas y pipas.

\section{Los orígenes de la almendra y su introducción en este ámbito}

El almendro tiene su origen en las regiones montañosas de Asia Central. La proximidad de las poblaciones silvestres naturales con centros de civilización en las montañas de Asia Central hizo posible su cultivo desde épocas remotas. La difusión a diferentes países asiáticos se vio favorecida por el hecho de que la semilla era al mismo tiempo la unidad de propagación y la parte comestible. De este modo se distribuyó por Persia, Mesopotamia y, a través de rutas comerciales, por todas las civilizaciones primitivas.

El almendro se cultiva en España desde hace más de 2.000 años, según indica F. Sigüenza (2011), probablemente introducido por los fenicios y posteriormente propagado por los romanos, ya que ambos lo hicieron motivo de comercio, como se ha comprobado por los restos hallados en naves hundidas. Su cultivo se estableció al principio en las zonas costeras, donde sigue predominando, pero también se ha introducido hacia el interior e incluso en las zonas del norte, donde el clima no le es muy favorable.

\section{El cultivo y la comercialización de la almendra}

La almendra es sin duda el mayor cultivo que se realiza en estas tierras. Existen centenares de hectáreas dedicadas a este cultivo. Pero no siempre esto ha sido así, a lo largo del tiempo ha cambiado el tipo de cultivos dedicados en estas tierras, siglos atrás los cultivos predominantes eran los pertenecientes a la trilogía que introdujeron los fenicios (trigo, vid y olivo), ahora como ya hemos explicado dos de ellos solo son para autoconsumo o para la caza.

En cambio se introdujo en su momento un cultivo que fue el almendro. Un cultivo de secano cuyo fruto se empieza a recolectar a mediados de agosto. Este fruto seco ha encontrado en estas tierras unas determinadas características que consiguen una calidad en su fruto que no se encuentra en otros muchos lugares del mundo. Este ámbito mediterráneo es el idóneo para su calidad en cuanto a sabor y textura. Pero esto es conveniente explicarlo con detenimiento pues esta calidad no se da en otros lugares del mundo donde este fruto suele tener un diferente sabor y textura.

En muchos lugares sobretodo Sudamérica y California existen grandiosas explotaciones de almendros, cuya calidad de la almendra no es ni tan siquiera comparable. Su sabor es seco, parece que se este comiendo madera, corcho, y la textura es de una almendra mucha más blanda que la nuestra. Esto se explica gracias a que nosotros tenemos 
muchas más horas de sol que ellos, y una ausencia de lluvias más irregular, que hace que nuestro fruto se macere más. En cuanto a las temperaturas son prácticamente las mismas, no existen grandes diferencias.

Al registrarse más precipitaciones y más regulares, el fruto no esta macerado, además otra característica que se da esas zonas es que la madera del árbol crece con mayor rapidez, esto aunque parezca que no tiene mayor importancia y sentido es muy importante, pues la madera al tener menos tiempo para hacerse dura, es mucho más flexible y se dobla con mayor facilidad. Además cuando un almendro se seca, o se arranca en esos lugares más húmedos, tiende a podrirse su leña de un año para otro, se pudre con una facilidad asombrosa. Esto ocurre también en zonas de España mucho más húmedas e incluso sin ir tan lejos en poblaciones limítrofes con Relleu como son Torremanzanas o Penáguila. La leña de los almendros de Relleu en las zonas de secano, es mucho más dura y consistente que en otras zonas y cuando más cálido y seco sea el terreno mucho más dura será la leña, aquí los troncos largos se utilizaban como jácenas.

En cuanto al sabor de la almendra esta es más dulce, cargada de azúcar y aceite que las de importación. Además de la dureza y la textura. En fin, que es una almendra mucho más buena en cuanto a calidad que la que se importa.

Pero, ¿por qué se importa almendra de estos países? La razón es muy sencilla y a la vez es indignante para los agricultores de la zona. La principal razón es el precio, mientras que aquí el producir una almendra supone unos costes elevados en cuanto a salarios, combustible y baja rentabilidad debido a la mano de obra y la poca mecanización a la hora de recoger los frutos, pues la mayoría de los bancales son estrechos y pequeños, en cambio en las zonas de Sudamérica y California el producir una almendra es mucho más barata, debido a los bajos costes de producción, los carburantes, la mano de obra y la elevada mecanización. Además los campos de cultivo son amplios y espaciosos lo que favorece la mecanización.

Esta es el principal factor pero existen otros como son los siguientes. Esta el factor político, denominando así los acuerdos de cooperación entre los diferentes estados que hacen que un producto agrícola tenga o pierda su valor dependiendo de los intereses que haya detrás, aunque la calidad sea muy inferior (Clairmont, 1997).

Otro factor también económico y también muy preocupante es el de las cooperativas, estas como están asociadas con otras en un ámbito internacional, compran a su antojo terrenos y explotaciones en otros países, para después comercializar esos frutos como nacionales y evitarse así pagar aranceles, con el prejuicio que eso supone para los agricultores nacionales (Bové, 2002).

Además, al estar en una economía de libre mercado, ya esas prácticas incluso se saltan, pues las principales fábricas de turrón esta zona, compran la almendra directamente de esos países internacionales, ignorando la calidad y lo que es más preocupante e indignante y denunciable, se pasan por el arco de triunfo el sello de calidad que se otorgo en su momento, como consejo regulador y de denominación de origen, a la marca del turrón de Jijona que con ese nombre o marca puede vender turrón por todo el mundo. Lo que se pretende denunciar, es que para vender bajo ese logo o distinción se estableció que el turrón se tiene que hacer con almendra autóctona, o nacional a lo sumo, y no elaborar el turrón con almendra de otros países con una materia prima de 
menor calidad, que después deben de arreglar añadiendo azucares y aceites que dicho materia prima no contiene.

Dicho esto y comparando las calidades, añadiré en cuanto a rentabilidad, que la almendra de importación es más rentable como producto acabado, ya que la nacional cuando se selecciona en los partidores de almendra, saca mucho más desperdicio y trozos que la almendra de importación.

Analizado este apartado de calidades y comparaciones con otro tipos de almendras que se comercializan en España y denunciando dichas prácticas porque deberían de ser denunciables y reprochables además de ilegales, pasaré a describir nuestra producción a nivel nacional y las comparaciones a nivel internacional.

\section{La producción nacional y su mercado}

La producción en España se concentra en las Comunidades del litoral mediterráneo: Cataluña, Comunidad Valenciana, Baleares (Mallorca), Andalucía y Aragón. Es el segundo productor mundial de almendra (tras Estados Unidos) con una producción en 2005 de 63.000 toneladas de grano (datos FAO) y una superficie cultivada de 560.000 hectáreas.

Figura 1. Producciones nacionales de almendras en grano. (Miles de toneladas). Años 2006 y 2007.

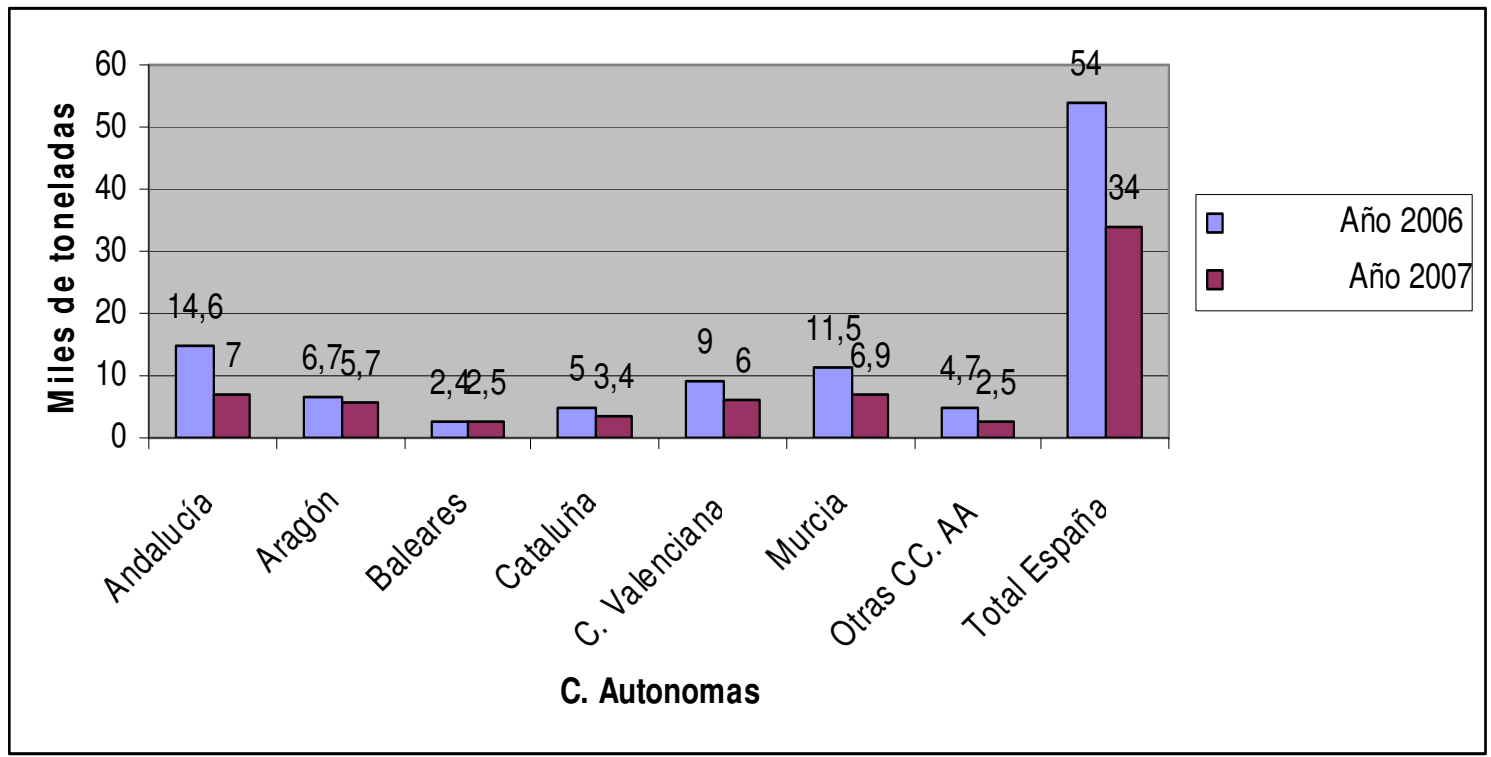

Fuente: Ministerio de Medio Ambiente, y Medio Rural y Marino. < http://www.sabormediterraneo.com>. Elaboración propia. 
Figura 2. Producción de almendra (grano) en 2005 (Miles de toneladas).

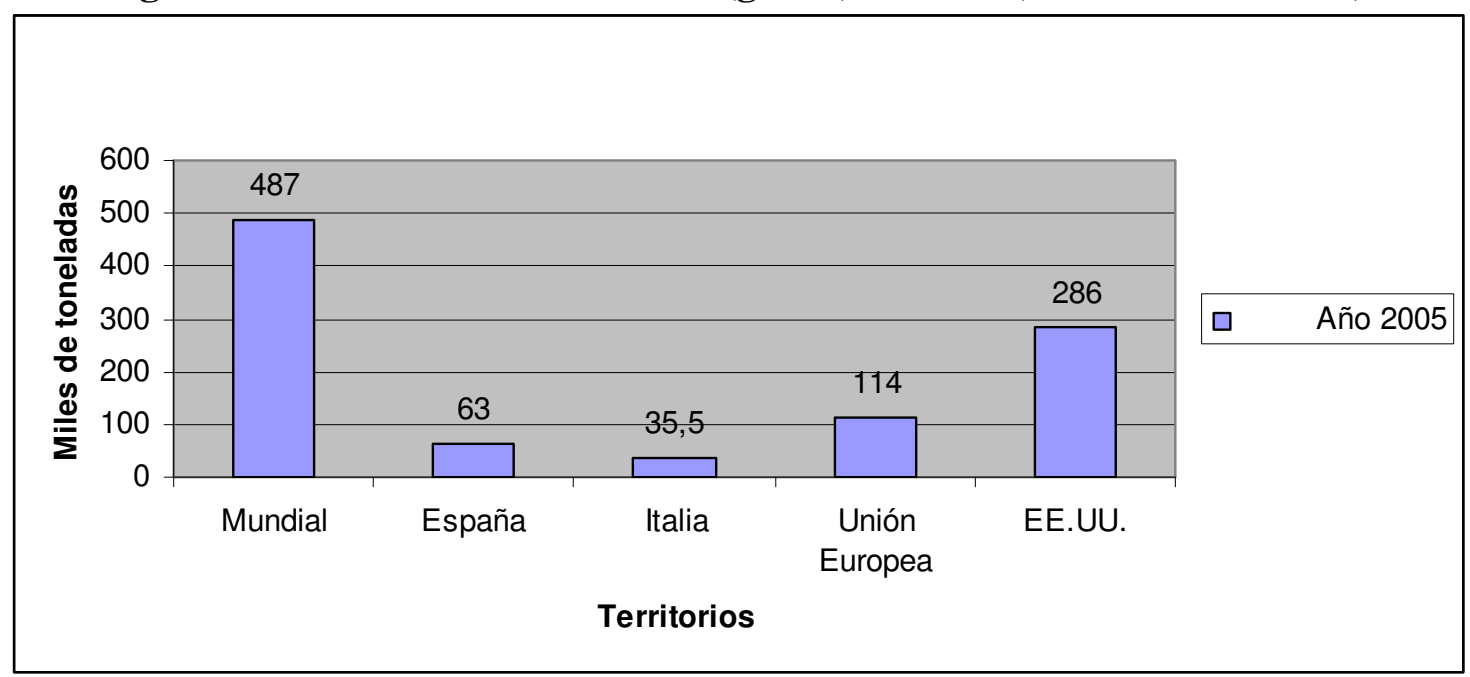

Fuente: Datos FAO. < http://www.sabormediterraneo.com>. Elaboración propia.

La producción española de almendras, al igual que la de otros países, resulta muy variable debido a la incidencia de las heladas, que afectan a la floración y al posterior cuajado del fruto. Este problema no sólo es de España, sino de los principales países productores, lo que determina grandes oscilaciones de precios de las almendras en los mercados internacionales.

Más del $55 \%$ de la producción española de almendra se destina a los mercados exteriores. El primer consumidor mundial de almendra es la Unión Europea y dentro de ella Alemania a donde se destina más del $30 \%$ de la exportación española de almendra.

En total España exportó en 2007 unas 51.000 toneladas de almendras, con y sin cáscara, de las cuales el $93 \%$ tuvo por destino la UE. En cambio las importaciones, unas 62.000 toneladas, procedieron en el $92 \%$ de terceros países, principalmente de EE.UU.

Con el objeto de satisfacer la creciente demanda en el mercado internacional, especialmente de los clientes europeos, se está introduciendo el cultivo orgánico de almendra. Asimismo existen en España varios centros de investigación en los que se está trabajando en la mejora genética del almendro para obtener así variedades que mejoren su capacidad productiva y su resistencia a condiciones adversas del medio, especialmente las heladas tardías, que constituyen el peor enemigo del almendro durante la floración (Sánchez, 1981). 
Figura 3. Evolución de precios en el campo en España (2006-2011). Variedad comuna. En euros.

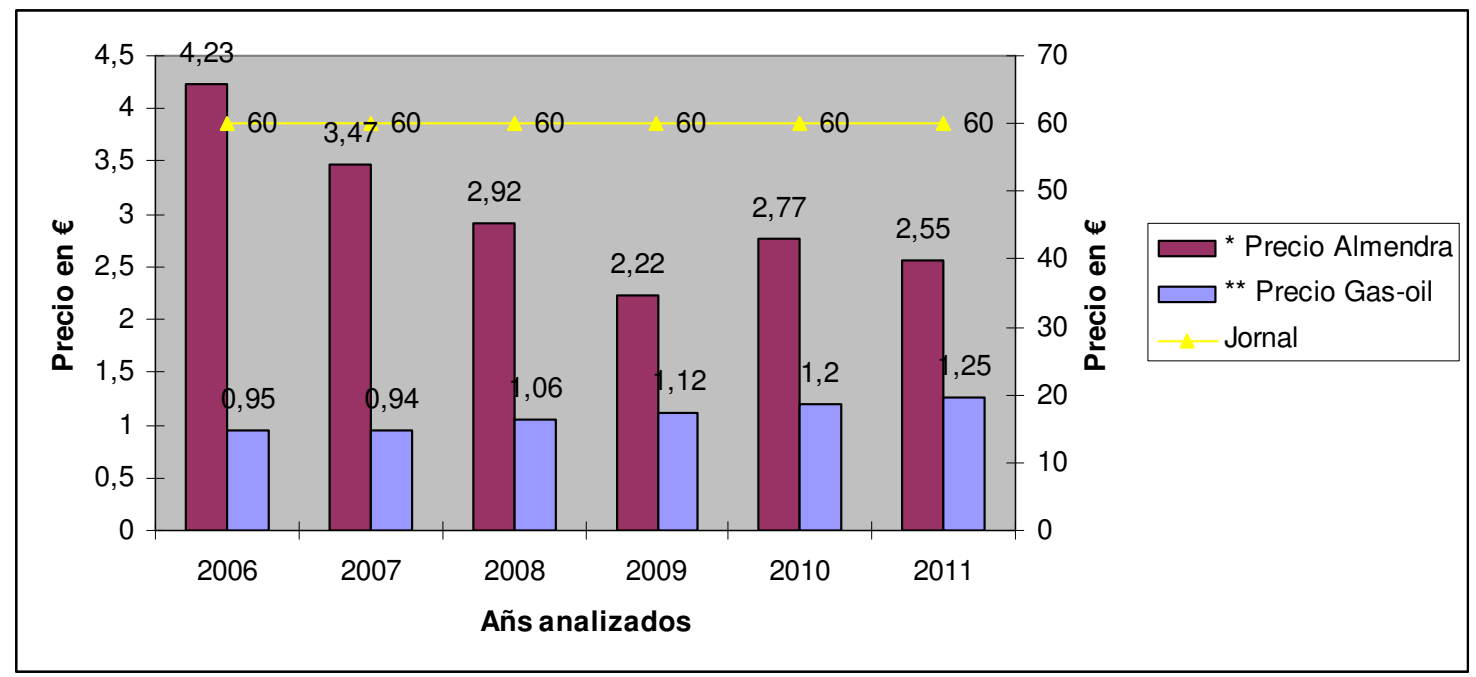

Fuente: Elaboración propia, con datos del boletín estadístico de hidrocarburos INH para el precio del gasoil, para los precios de la almendra histórico de la lonja de Reus y los precios jornal que se pagan a pie de campo.* Precio de la almendra comuna en grano. ** Precio del gasoil tipo A, existe un gasoil bonificado tipo B para la agricultura pero no aparecen datos en el INH.

Como se observa en la figura 3, la evolución del precio de la almendra es de tendencia a la baja. Se trata del valor pagado a la almendra comuna en grano, en la lonja de Reus, una de las más importantes de España para este tipo de mercado. Desde el año 2006 que alcanzó un valor medio anual de 4,23 hasta el valor medio anual en 2011 que es de 2,55. Se aprecia claramente como ha experimentado un descenso de 1,80€ aproximadamente. En cambio, el precio del gasóleo ha experimentado una subida considerable, pasando de $0,95 €$ en 2006 a los $1,25 €$ que esta a día 25 de mayo en las gasolineras. El jornal en cambio no ha variado, se paga al mismo precio durante estos últimos años. Es una estimación aproximada, pues al ser un trabajo eventual y "variable" (no se cotiza a la Seguridad Social) se paga un precio estipulado de 60 euros.

Este precio que aparece en la lonja de Reus es el precio en grano, ahora para calcular el precio de la almendra en cáscara, habrá que dividir por el rendimiento que se obtenga de ella. Dependiendo del rendimiento se obtendrá un valor u otro. Si da un $25 \%$ (: 4), si es un $20 \%$ (: 5). Ejemplo: 4,23: 4 (rendimiento $25 \%$ ) = 1,05 € el kilo de almendra en cáscara. Ya que se calcula que para cada kilo de almendra en grano se necesitan 4 o 5 kilos de almendra en cáscara, de ahí la importancia del rendimiento. Cuanto más alto sea el rendimiento quiere decir que se necesitan menos kilos de almendra en cáscara y por lo tanto mayor valor se obtendrá.

Para la realización de este apartado me hubiera gustado elaborar una gráfica con una mayor proyección, basándome en el histórico de los últimos 30 años, pero no ha podido ser. En la lonja de Reus (la más importante) el histórico que se facilita es a partir de 2006. En cambio, el gasóleo sí aparece en el boletín estadístico de hidrocarburos desde el año 1973. 
Cabe mencionar la diferencia existente en las lonjas de compra y venta de productos, en algunas se paga alguna variedad un poco más cara que otra y viceversa. Mi intención era plasmar la decadencia de los precios de la almendra y el aumento de los costes (gasóleo) y creo que en seis años algo se puede apreciar.

La figura 4 recoge los precios de la almendra marcona en la lonja de Reus.

Figura 4. Evolución de los precios en la agricultura en España (2006-2011). Variedad Marcona. En euros.

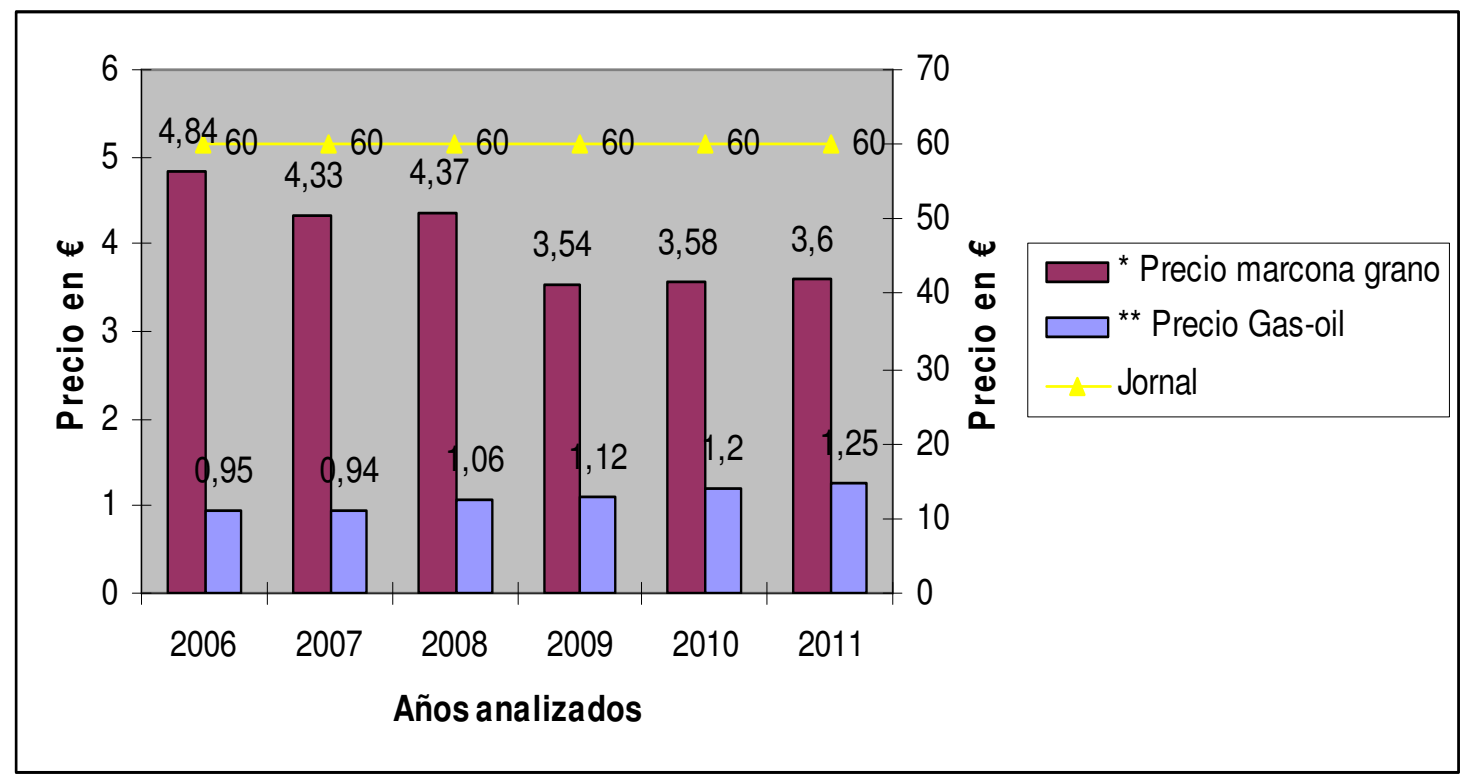

Fuente: Elaboración propia, con datos del boletín estadístico de hidrocarburos INH para el precio del gasoil, para los precios de la almendra histórico de la lonja de Reus y los precios jornal que se pagan a pie de campo.* Precio de la almendra marcona en grano. ** Precio del gasoil tipo A, existe un gasoil bonificado tipo B para la agricultura pero no aparecen datos en el INH.

A continuación y para terminar este punto, mostraré el albarán y el ticket con el peso de la almendra que coseché, y el precio que percibí por parte de la cooperativa a la que pertenezco (MAÑAN). La fecha es el 21 de diciembre de 2010. 


\section{Figura 5. Albaran y ticket propio.}

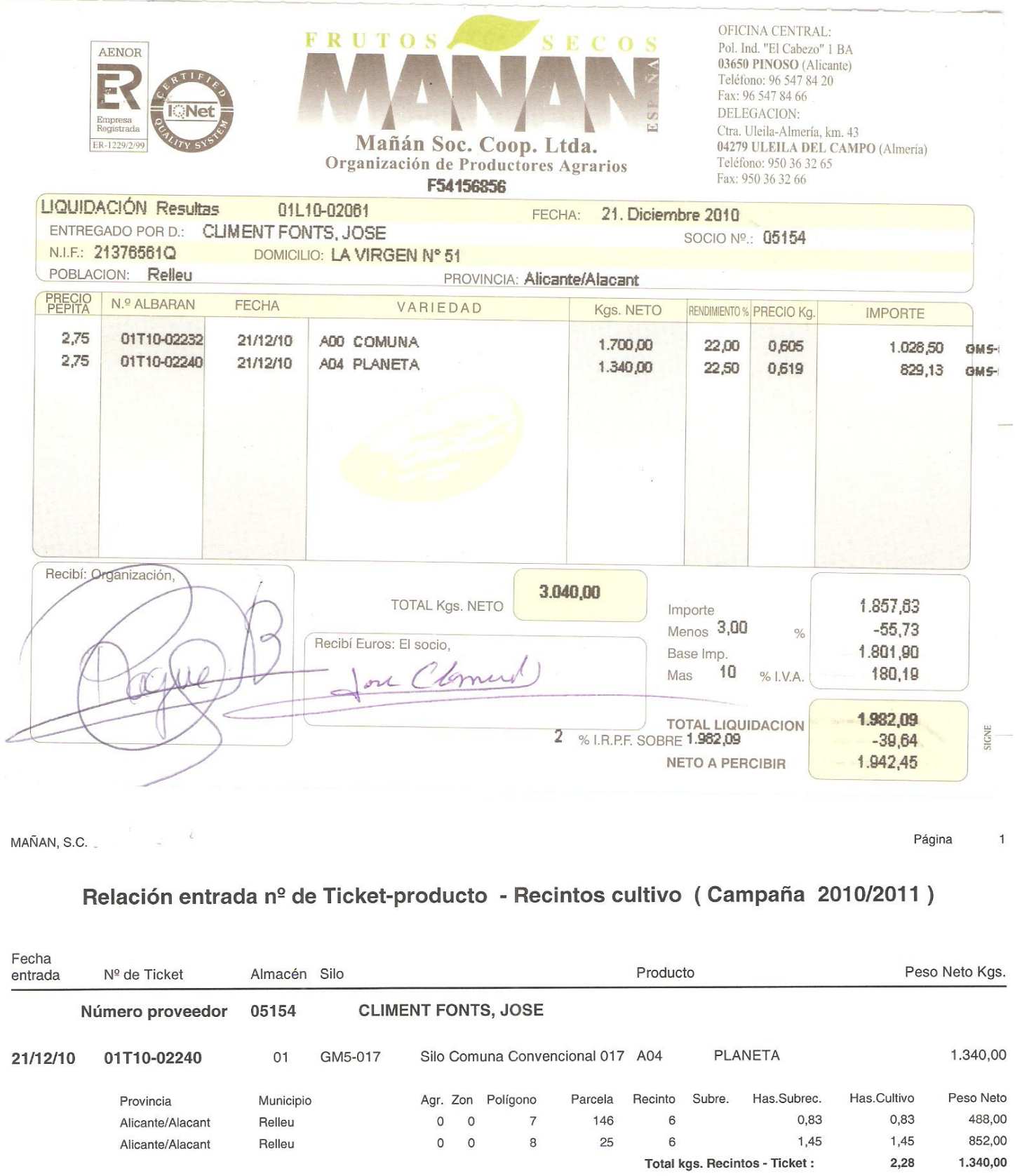

Fuente: Ticket propio.

\section{Características de las almendras}

Las diferentes variedades de almendras se diferencian por algunas de estas características: por su cáscara (si es dura o blanda), por su floración (si es temprana o tardía, dependiendo de las temperaturas si no la flor en sí puede helarse), tipología del grano de almendra (si es plano, o gordo; si tiene uno o dos), por su peso, por su tamaño, su sabor. Otra importante es el rendimiento del fruto con varios parámetros variables.

Su cáscara, esta puede ser una cáscara normal (dura) que son las que corresponden con la mayoría de variedades, o una cáscara blanda que corresponde con la variedad 
amollar, este tipo de almendra tiene una cáscara blanda, que se rompe fácilmente con los dientes.

Otra característica es la floración y aquí depende mucho de las temperaturas. La floración del almendro más común se da entre los meses de enero y febrero, retardándose si durante diciembre y el principio de enero el frío es importante pero no retardándose más allá del mes de febrero. Además influyen otros factores detallados en el apartado de floración. A pesar de todo hay variedades como la marcona y la guara que su floración es más tardía, por dos razones: la primera variedad es por que es característica de elevadas altitudes y por tanto expuesta a fríos más tardíos. La guara es una nueva variedad que se obtenido en programas de mejoras españoles, y se ha introducido en esta zona. Esta variedad se ha creado ya con una floración tardía para evitar así que se hiele.

En cuanto a la tipología del grano, existe una variedad denominada planeta muy común por esta zona cuyo grano presenta una característica plana y alargada y se distingue con otras propiedades como el sabor y la estructura (la mayoría lleva dos granos). El resto de las variedades, el grano es alargado y más gordote.

Por el peso también se diferencian, tanto por el peso de la cáscara, como por el peso del grano. Unas variedades pesan más que otras. Además obviamente cuanto mayor sea la almendra mayor peso tendrá, siendo el tamaño otra característica a tener en cuenta.

En cuanto al sabor, este depende básicamente de la dulzura, además este fruto seco como el resto contiene un elevado contenido de aceite, propiedad que se aprecia claramente cuando se elabora el turrón.

El rendimiento es fundamental ya que es sobre esta característica sobre la que se establece el precio del producto en el mercado. Se establece siguiendo unos parámetros variables como son la humedad, la calidad y el peso. Estos parámetros se analizan mediante unas muestras recogidas en el momento de la venta del producto a las cooperativas o a un mayorista. El sistema es el siguiente, se recogen unas muestras al azar de entre todo el montón de almendras, se parten y se analiza el grano. En función de cuantos granos están sanos o enteros se seguirá uno de los parámetros, este podríamos calificarlo de parámetro visual (a simple vista). Al hilo de este parámetro se establece el siguiente que es el peso, para calcular el porcentaje. Normalmente este porcentaje oscila entorno al $22 \%$, esto quiere decir que para sacar un kilo de almendras sin cáscara se deben partir unos cuatro kilos de ésta. Y por último está el parámetro de la humedad, para ello se emplea un aparato que mide el contenido de agua de los granos seleccionados, este es tan determinante como los anteriores pues cuanto mayor humedad tengan menor precio alcanzará en el mercado. Para conseguir que el grano tenga poca humedad lo ideal es cosechar la almendra cuanto más seca mejor y aún así, cuando esté ya con la cáscara pelada dejarla secar al sol de septiembre, todo para conseguir un mejor rendimiento, para que luego repercuta en el precio final. 


\section{Diferentes variedades de almendras}

Analizadas las características más principales de las almendras de esta zona, enumeraré las distintas variedades que existen en dichos campos detallando cada una de sus características.

La primera variedad que señalaremos es una de las más extendidas y abundantes por todo el municipio, se trata de la denominada Castellet. Esta variedad es la que mejor se adapta a las condiciones climáticas de esta zona y por lo tanto de ahí que sea la más abundante en estos campos. Es un árbol de medias y bajas altitudes. A parte de su adaptación al medio, obtiene un buen rendimiento. En cuanto a la dureza de la cáscara, esta es bastante dura, consistente y no se rompe con facilidad. El grano es alargado, pero guarda una simetría con su grosor. Tiene un sabor dulce, aunque no sea la más sabrosa. Su cotización es media, no es de las mejor pagadas. En cuanto a su floración, se produce al mismo tiempo que la gran mayoría de variedades, pero con una característica negativa, existen diferencias apreciables entre años en lo que respecta al rendimiento del árbol, ya que un año produce en demasía y al año siguiente su rendimiento baja considerablemente, alternando la producción de unos años a otros.

Siguiendo con las variedades de zonas medias y bajas altitudes, aparece la Planeta. Para mí es la almendra con mejor sabor de todas, es dulce y muy jugosa. Es una variedad muy apreciada en la zona dado su sabor y su rendimiento, muchas de ellas tienen dos granos. Como su nombre indica es una almendra plana y alargada, no guarda una simetría con su grosor. Una característica negativa de esta variedad es que cae del árbol con facilidad, se debe recoger de las primeras pues el viento las derriba con facilidad cuando están maduras. Estas dos variedades que hemos analizado son las más abundantes en este territorio, las siguientes tienen mucha menor presencia debido a varios factores que iremos describiendo en sus análisis.

Sin duda esta variedad es la que más se comercializa y de mejor calidad a nivel mundial, la Marcona, originaria de la provincia de Alicante (según www.fruitveg.com), pero que aquí debido a sus características no es muy abundante. Esta variedad se cultiva en zonas más altas, puesto que se adapta mejor al frío, su floración es más tardía, luego aquí su producción se limita a determinadas zonas de montaña, su recolección se atrasa hasta finales de septiembre o principios de octubre. Su grano es gordo y redondeado. Es la más cara y demanda por la industria repostera y turronera. Desprovista de su cáscara, se tuesta hasta que adquiere el tono deseado para la elaboración de turrones duros o blandos. Además, sirve de base para las Denominaciones de Origen Jijona y Alicante, así como para la Denominación de Calidad Mazapán de Toledo y los tradicionales guirlaches aragoneses. Asimismo, al tener en su composición menos aceite, se suele destinar a la producción de almendras fritas. Una característica curiosa es que ninguna de ellas saca el gano doble.

La Guara. Esta variedad se esta introduciendo en la actualidad en esta zona, debido a la aplicación de las políticas de la PAC, puesto que al potenciar y subvencionar el arranque y nueva plantación de los árboles, algunos campesinos optaron por plantar e injertar esta variedad en nuestros campos. Tiene varias cualidades que la hacen atractiva, como es una tardía floración y una temprana maduración. Lo cual hace que se garantice su producción puesto que evita las heladas y las tormentas de últimos de septiembre. Su grano es alargado, simétrico y su cáscara es dura. Una característica de 
de esta variedad es que su peso es inferior comparado con el resto. Pues con el mismo volumen de almendra por ejemplo de Castellet, con esta variedad su peso es muy inferior, echo que influye en el rendimiento y repercute en el precio.

La variedad Amollar es poco abundante en esta zona. Se denomina así porque su cáscara es blanda. Esta variedad se cultiva principalmente en EE.UU. y Portugal (Fruitveg.com). Existen varias variedades de amollar en esta zona, pero la más significativa es la Blanqueta. Una almendra con la cáscara blanca y con granos dobles en su mayoría. Su floración es igual que las mencionadas con anterioridad a excepción de la marcona. En esta zona se utiliza para tostar con su cáscara.

La Punxeta, variedad que tiene como característica que su cáscara y su grano son puntiagudos. Su cáscara es de una dureza media. Se cultiva en zonas medias-bajas y su floración es en la misma época que el resto. Otra de las características es que su fruto en el árbol es muy abundante y que si no esta muy maduro no cae con facilidad.

La siguiente variedad es meramente testimonial en esta zona se trata de la Desmayo. La principal zona de producción de esta variedad es el valle del Ebro, desde Zaragoza hasta Tarragona y en las provincias limítrofes de Lérida y Teruel (según fruitveg.com). El árbol es de porte llorón. Existen varios tipos locales en regiones españolas, siendo el más conocido Desmayo Rojo. El grano es alargado, puntiagudo, liso y de cáscara dura y se comercializa con el nombre de Larguetas. Su floración es muy precoz y la maduración muy tardía. Aquí se da en zonas elevadas y frescas, siendo muy reducida su producción y con elevado riego de heladas.

La Abalde es la variedad que presenta la cáscara más dura de todas. Es una almendra redondeada, de grano redondo también y con una floración calcada al resto de las variedades antes mencionadas. Como el resto de las tres anteriores, su presencia es meramente testimonial, pues no tienen un gran rendimiento, están para facilitar y permitir la floración, ya que como veremos a continuación esta debe ser cruzada y deben de existir diferentes variedades para que cuaje. Esta variedad se utilizaba para realizar horchata de ella, puesto que es una almendra muy dulce.

La almendra Borde más que una variedad es más bien el tipo de almendra original sin que el almendro este injertado. Este grano es amargo, incomestible, normalmente redondeado y con una cáscara dura. Suelen presentarse en los márgenes y siempre en árboles sin injertar. El echo de que aparezcan estas almendras a la hora de venderlas en su conjunto, hace que el precio final descienda puesto que el rendimiento y la dulzura como ya hemos visto influirán en el precio del producto.

Normalmente a la hora de comercializar la almendra y para alcanzar un precio razonable y equitativo a la hora de la venta, o bien cuando se recolecta se separa cada variedad en diferentes sacos (para saber cual es cual) para venderlas por separado ya que cada variedad alcanza un precio en el mercado o bien se venden todas juntas bajo la denominación de Comunas, teniendo en cuenta los parámetros indicados con anterioridad a la hora de la obtención del precio final. 


\section{La floración}

La época de floración en el almendro tiene una gran importancia porque influye directamente en las posibilidades de obtención de una buena cosecha, debido a la incidencia de tres factores: la polinización, las lluvias y las heladas.

\section{La polinización}

Las variedades tradicionales de almendro son autoincompatibles, por tanto resulta indispensable la polinización cruzada para producir una cosecha. Debido a que el producto comercial del almendro es la semilla, esta cosecha solo se puede obtener si los procesos de polinización y fecundación tienen lugar de manera correcta. Para ello se diseñará la plantación con variedades intercompatibles de floración simultánea, circunstancia que hasta recientemente no se había tenido en cuenta. Cada año la fecha de floración puede variar según las condiciones climáticas, sobre todo las temperaturas para cubrir las necesidades de horas-frío de cada variedad, pero siempre la secuencia de floración de las distintas variedades es aproximadamente la misma. Aunque se produzcan pequeños solapes entre las floraciones de ambas variedades, éstos nunca son lo suficientemente extensos como para asegurar su interpolinización.

Se debe colocar un mínimo del $33 \%$ de polinizadores que coincidan plenamente en la floración con la variedad elegida, distribuidos en filas alternas y colocando de 4 a 6 colmenas por hectárea.

Actualmente, esta falta de coincidencia puede resolverse con la plantación de variedades autógamas, entre las que la Guara está muy extendida.

La xenia es un fenómeno que se produce cuando tiene lugar la fecundación cruzada con almendro salvaje (amargo), dando almendras amargas (según www.infoagro.com).

\section{La lluvia}

Las lluvias durante la floración impiden el vuelo de las abejas, que son los agentes transportadores de polen más efectivos desde una variedad a otra con el fin de conseguir una efectiva polinización. Las abejas desarrollan mayor actividad cuando la temperatura ambiente oscila entre $15-16^{\circ} \mathrm{C}$. Su actividad decrece al descender esta y llega a anularse por debajo de los $10-12^{\circ} \mathrm{C}$. Tampoco realizan vuelos ni actividad si el viento es superior a $24 \mathrm{~km} / \mathrm{h}$. El efecto de las lluvias sobre el posible lavado del polen en la flor y con ello la imposibilidad de su polinización, parece ser según las estadísticas de producción, muy reducido.

\section{Las heladas}

Se trata de un problema reincidente en muchas zonas de interior, aunque también en zonas costeras se pueden presentar heladas en el momento de la floración o inmediatamente después, lo que en algunos casos puede anular totalmente la cosecha. 
La posición de la parcela también afecta a la incidencia de las heladas, por tanto en el momento de elección de la plantación, hay que tener en cuenta la disposición geográfica de la parcela.

Para superar el problema de las heladas se han buscado variedades de floración tardía, además se recomienda el cultivo en laderas soleadas, ya que permite escapar a las heladas y potenciar la actividad de las abejas.

\section{El cultivo de la aceituna}

El cultivo de la aceituna se esta extendiendo mucho por la zona que nos ocupa por varias razones:

- Falta de rentabilidad del almendra, provocado por la sequía y las políticas de la PAC, de arranque y nueva plantación que se subvenciono en los años 90.

- Abandono progresivo de la actividad por baja rentabilidad de la agricultura, por el aumento del precio de la mano de obra y los carburantes.

- Estas dos razones derivan para que se planten más hectáreas de olivos al año, por necesitar menos mano de obra y ser un árbol más resistente a la sequía y de hoja perenne. El agricultor, por tanto, siempre ve el árbol verde aunque no produzca.

El cultivo de la aceituna esta muy extendido por todo el mundo (Hobbelink, 1987), con múltiples variedades o clases, distinguiendo algunas para comer y otras para la fabricación del aceite. En esta región hay cinco variedades que son las más representativas o abundantes. Son las siguientes: manzanilla (que es la más extendida y abundante), la alfafara (la mejor para el aceite), la gordal o grossal, cuernet o callosina y la blanqueta (esta última se sitúa en zonas más altas debido a su mejor aclimatación al frío). Estas últimas son las menos abundantes, una por clima (blanqueta) y las otras se utilizan sobretodo para comer y para la floración, pues debe de haber variedad para que la flor cuaje o polinice.

La época de floración del olivo se da en los meses de abril y mayo. El fruto se empieza a recoger entre los meses de noviembre y diciembre, siempre condicionado por el frío o la lluvia que pueden adelantar o retrasar la cosecha.

Este cultivo requiere de unos cuidados básicos tales como una correcta limpieza de sus ramas jóvenes, una época específica de labrado o una distancia adecuada entre otros olivos o cultivos de cara a la época de florecimiento. En este proceso el viento y las abejas son fundamentales para una correcta polinización.

Importante es también que en esta época el tiempo no sea impertinente y no aparezcan muchos días nublados, ya que esto puede perjudicar al cultivo dejando caer la flor. Así como las fuertes olas de calor sahariano de los meses de julio y agosto.

El cultivo de la aceituna fue introducido en España y concretamente en esta región por los fenicios junto con la vid y los cereales, según indica F. Sigüenza (2011). 
La producción en España de este cultivo es muy elevada y representativa siendo el país con mayor producción mundial según un estudio realizado por el consejo oleícola internacional del año 2000 (editando el libro Catálogo Mundial de Variedades de Olivo), del cual se han extraído algunos datos para la realización de este apartado.

La figura 6 refleja los siguientes datos. Esta es la relación de los países productores de aceite del mundo y sus producciones, así como la superficie olivarera en hectáreas de cada uno. Como se aprecia, la superficie en España es de más de dos millones de hectáreas. El país que le precede es Túnez con algo más de un millón seiscientas mil hectáreas cultivadas. Después el siguiente es Italia con un millón ciento cuarenta y siete mil hectáreas y luego ya vendría Turquía por debajo del millón.

Como se puede apreciar en la figura 7, España es el principal país en hectáreas de cultivo de la aceituna de la Unión europea, seguida de Italia con la mitad de superficie cultivada. Y es que la suma de la superficie cultiva por el resto de los países a excepción de Italia es de 2.070.610 hectáreas, lo que supone que no lleguen a igualar la superficie que dedicaba España en el año 2000 a este cultivo.

La figura 8 muestra que Europa es la principal región en cultivo de aceituna del mundo, muy por encima del resto de las regiones del mundo, y en especial España, que es el mayor con una amplia diferencia con el resto.

La producción de aceite en España en los años 1996/97 fue de 947.300 toneladas, en la campaña 1997/98 fue de 1.077 .000 toneladas y en 1998/99 fue de 789.200 toneladas, según los datos del Consejo Oleícola Internacional del año 2000), no he encontrado datos más próximos tan fiables.

\section{Principales variedades}

En el siguiente punto se trata las diferentes variedades que se cultivan en la población de Relleu, así como las diferentes características del árbol, del fruto y del endocarpo. Además de una serie de enfermedades a las que están expuestas estas variedades. También se trata algunas formas de recolección.

Es la variedad de olivo y aceituna más expandida y común en este ámbito de estudio. El vigor del árbol es bajo-medio, con porte abierto y una densidad de la copa media. Su capacidad de enraizamiento es media, tanto por estaca como por estaquillado semileñoso en nebulización. Es de origen española. Su entrada en producción es precoz. Su época de floración es media y su polen presenta elevada capacidad germinativa. Aquí se cultiva sin polinizadores, no obstante fuera de España se ha observado un aumento del cuajado con polinización cruzada. Este olivo esta floreciendo tal y como se aprecia en la foto su color amarillento. La hoja del olivo tiene forma elíptica, de longitud y anchura media y de una curvatura longitudinal del limbo plana. 
Figura 6. Superficie olivarera mundial (en hectáreas).

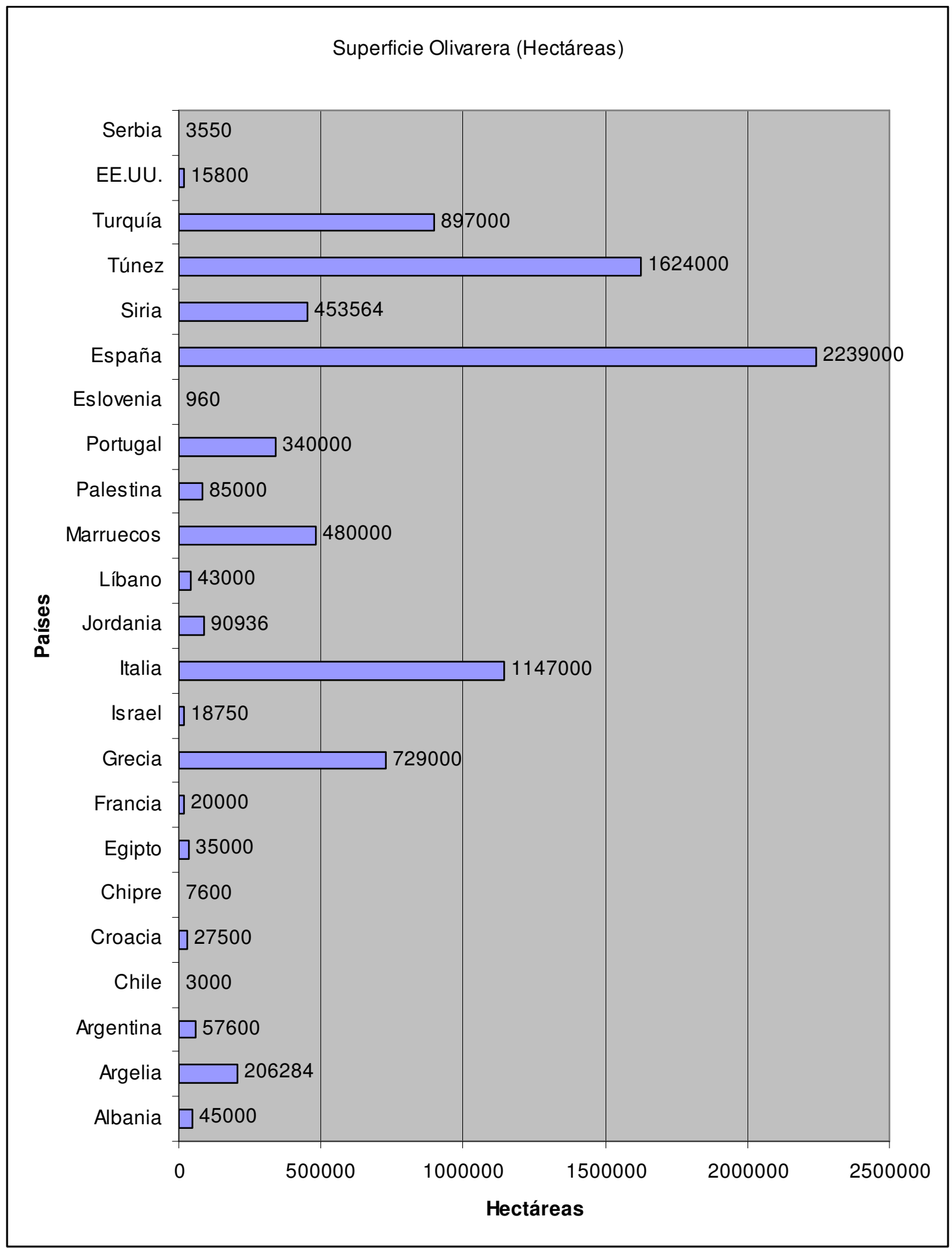

Fuente: Elaboración propia a partir del Catálogo Mundial de Variedades de Olivo, 2000. 
Figura 7. Superficie olivarera en Europa (en hectáreas).

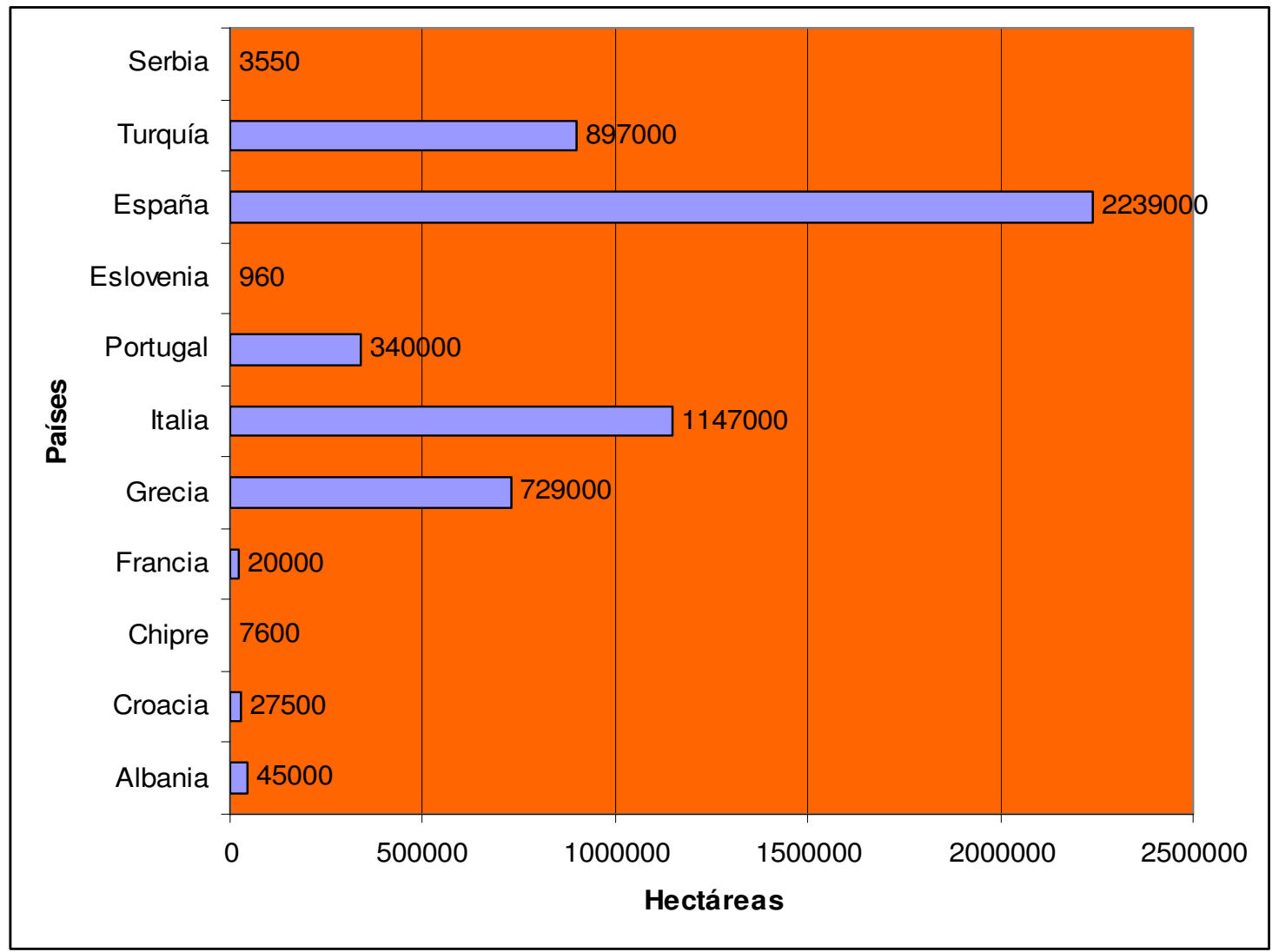

Fuente: Elaboración propia a partir del Catálogo Mundial de Variedades de Olivo, 2000.

Figura 8. Superficie olivarera mundial (en hectáreas).

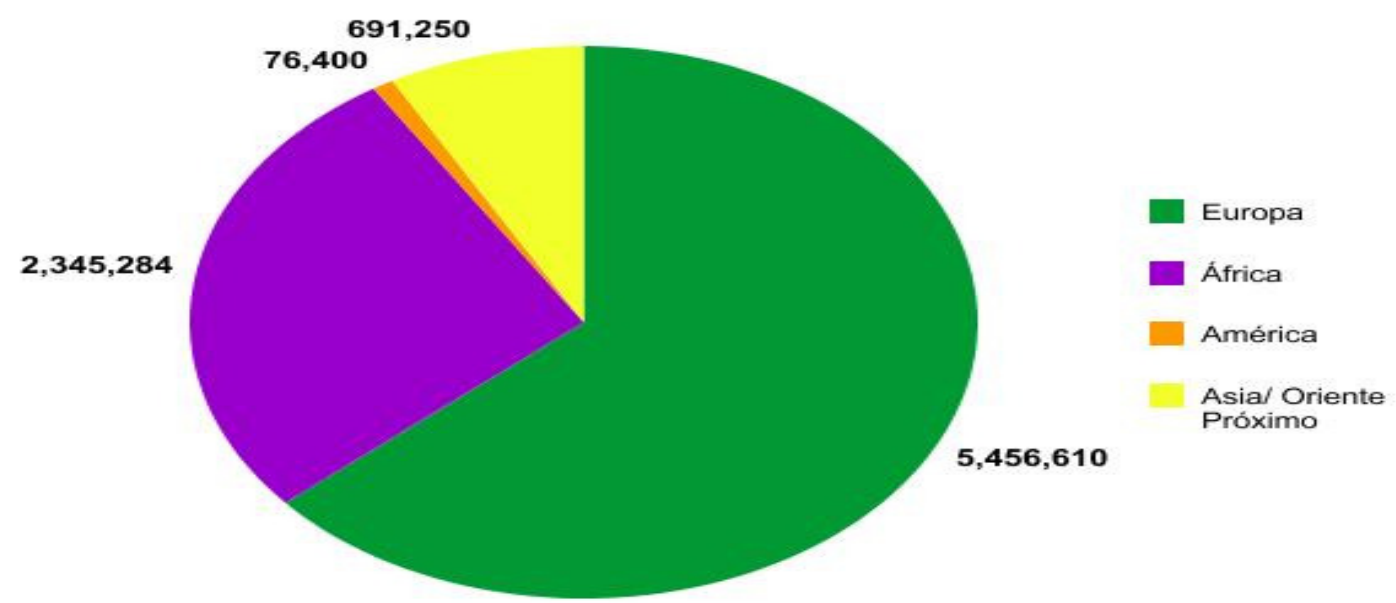

Fuente: Elaboración propia a partir de Catálogo Mundial de Variedades de Olivo, 2000. 
En cuanto a la aceituna, su productividad es elevada y alternante. Su época de maduración es precoz y presenta elevada resistencia al desprendimiento. Se utiliza de las dos maneras posibles, sirve para mesa y para aceite. Para mesa se recoge verde para su aderezo por fermentación al estilo sevillano, con sal y agua. Es la variedad de mesa más apreciada, dada su calidad. Para el aceite su contenido es medio pero de elevada calidad y estabilidad. La separación de la pulpa del hueso es fácil. Su peso es elevado y su forma es esférica y simétrica. Su ápice es redondeado, de base truncada y las lenticelas son abundantes y pequeñas. Dependiendo de las lluvias que hayan caído cuando el fruto esta madurando, su contenido en agua y aceite será más o menos elevado, cuanta más lluvia más agua absorberá.

El hueso o endocarpo es de peso elevado y de forma ovoidal, ligeramente asimétrico. De ápice redondeado y con terminación con mucrón, de base apuntada y con una superficie rugosa.

Se considera muy sensible a verticilosis y sensible a repilo, tuberculosis, lepra y mosca. De hecho cuando esta muy madura y esta enferma salen unos pequeños gusanos o larvas blancas que impiden que se puedan conservar durante mucho más tiempo. Si esta sana se conserva durante mucho más tiempo.

Modo de recolección: mediante vareo tradicional con la colocación de telas y además se esta experimentando la mecanización, con un vibrador o con paraguas.

Esta variedad es abundante pero es característica de zonas medio-altas puesto que resiste muy bien el frío y es susceptible a la sequía. Enraíza fácilmente por estaquillado y suele usarse como patrón de otras variedades. Es de origen española y su principal destino es el aceite. El vigor del árbol es medio, con porte abierto y la densidad de la copa es espesa. La forma de la hoja es elíptica de longitud y anchura media y de curvatura longitudinal del limbo plana.

La maduración de sus frutos es tardía y suelen presentar una resistencia grande al desprendimiento, sino esta muy maduro no cae con facilidad cuando la recolección es artesanal mediante vareo. El contenido en aceite de sus frutos es de bajo a medio y presenta un índice de extractabilidad muy bajo. Sin embargo, el aceite es de buena calidad.

El peso del fruto es medio, de forma ovoidal y asimétrico. Contiene abundantes y pequeñas lenticelas. El endocarpo es de peso elevado, de forma elíptica y ligeramente asimétrico. Su ápice es apuntado con base redondeada con terminación en mucrón, y una superficie rugosa.

Se considera muy resistente a tuberculosis y susceptible a repilo. Asimismo, se cultiva en diferentes comarcas de las provincias de Albacete, Valencia y Alicante. Siendo la comarca del valle de Ayora y Almansa la variedad principal.

El modo de recolección es el mismo que el resto de las variedades, esta el método tradicional mediante vareo o una a una (munyir) o ordeñar. A estos métodos se ha añadido la colocación de unas mantas de tela fina con agujeros (para que la hierba crezca por dentro de ellos, ya que suelen colocarse a principios de octubre y se retiran cuando el fruto esta bien maduro, allá por diciembre) y que además permite que cuando 
llueve el agua filtre bien en la tierra. También se esta utilizando unas maquinas que hacen la función de varear, mueven las ramas y permite que caigan las aceitunas cuando estas están maduras. Otra que se esta empleando más reciente es la maquina paraguas.

Variedad apreciada por su resistencia a la sequía. Enraíza fácilmente y se considera autocompatible. Su entrada en producción es media. Es una variedad no extendida por el resto de España aunque su origen se español, se concentra básicamente en las provincias de Murcia y Alicante. Es por tanto una variedad secundaria, su función es polinizadora. El árbol es de porte abierto y de mediano vigor, además la densidad de la copa es media, en la foto esta está recién limpiada. La hoja es de forma lanceolada, con una longitud larga y estrecha y la curvatura longitudinal del limbo es plana.

La maduración de sus frutos es tardía y presentan una elevada fuerza de retención que dificulta su recolección. Como aceituna de mesa es apreciada por la calidad de su pulpa y por aguantar mucho tiempo aderezada. La relación pulpa/hueso es media.

Es apreciada por su productividad elevada y constante, y por el elevado contenido en aceite y la calidad del mismo. El peso del fruto es medio de forma alargada y asimétrico. Se caracteriza por su ápice que es de forma apuntado y con una base truncada. Presenta abundantes y pequeñas lenticelas.

El hueso es asimétrico, de peso medio y de forma alargada. Se ápice es apuntado y con una superficie lisa.

Se considera susceptible a repilo y resistente a tuberculosis y mosca.

Es una variedad de origen español y su principal destino es el consumo en mesa. Variedad vigorosa cuando está injertada, presenta escaso vigor en sus propias raíces. Se considera tolerante al frío invernal y a la humedad pero es susceptible a la sequía. Es una variedad bastante testimonial en esta zona. Su capacidad de enraizamiento por estaquillado semileñoso es muy baja, por lo que normalmente se recurre al injerto para su propagación.

Su producción es media. Su época de floración es media, se considera autoincompatible, de elevado aborto ovárico y con polen de muy baja germinabilidad. El árbol es de vigorosidad media, con porte erguido y de una densidad en la copa media. La forma de la hoja es elíptica- lanceolada, de longitud larga y de mediana anchura. La curvatura de longitudinal del limbo es plana.

Su productividad es baja y alterante. La época de maduración de sus frutos es precoz y se destinan exclusivamente para aderezo, pues su contenido en aceite es muy bajo. Es apreciada en la mesa por su tamaño más que por su calidad. Su peso es muy elevado, de forma ovoidal y ligeramente asimétrico. El ápice es redondeado y su base también con abundantes y grandes lenticelas.

Su hueso es de peso elevado y de forma alargada, ligeramente asimétrico, con el ápice y la base apuntados y con terminación en mucrón. Su superficie es escabrosa. La recolección es manual, ordeñadas. Es resistente a repilo y susceptible a tuberculosis y aceitunas jabonosas. 
Es una variedad que se esta introduciendo en esta zona, de ahí que los olivos sean jóvenes en su mayoría. Además de la provincia Alicante, Valencia y Murcia se esta difundiendo ligeramente por Cataluña. Su origen es español, como todas las anteriores. Es una variedad de vigor reducido, considerada rústica por su adaptación a la sequía y la resistencia al frío. La capacidad de enraizamiento es elevada.

La entrada en producción es precoz, al tercer año ya producen. Su época de floración es tardía y su polen presenta baja germinabilidad.

El árbol es de vigor bajo y de porte erguido y la densidad de la copa es media. La forma de la hoja es elíptica y corta de longitud y de media anchura. La curvatura longitudinal del limbo es hiponástica.

La producción es elevada y constante. La época de maduración de sus frutos es media y la fuerza de retención de los mismos es relativamente elevada, lo que dificulta su recolección mecanizada. Su contenido en aceite es elevado y su calidad es apreciada, siendo este su único destino. Su aceite es dulce y afrutado, pero de muy baja estabilidad. El peso de la aceituna es bajo, de forma esférica y simétrica. Su ápice es redondeado, con una base truncada, y abundantes y pequeñas lenticelas.

El hueso es de peso bajo, de forma ovoidal y simétrico. El ápice es redondeado, con su base apuntada y un a superficie lisa. Se la considera resistente a repilo y tuberculosis.

\section{NUEVA ALMAZARA DE RELLEU}

Se trata de una iniciativa privada de una familia con larga tradición oleícola, donde varias generaciones familiares han desarrollado esta actividad. En esta localidad durante todo el siglo XX existían dos almazaras dentro del casco urbano, dentro del pueblo, que funcionaban mediante la ayuda de la fuerza animal. Además en algunas fincas grandes con gran producción de aceite también tenían a menor escala su propia almazara pequeña. Todas ellas eran almazaras antiguas, tradicionales que poco a poco fueron cayendo en desuso además de que sus deshechos y vertidos ahora deben de ser tratados, con lo que aquella actividad suponía una agresión al medio ambiente. Fruto de estas nuevas políticas de los años 90, este empresario decidió emprender la modernización de esta actividad de obtención del aceite (modalidad maquila), construyendo una almazara en primer lugar dentro del pueblo y a los pocos años la trasladó a las afueras, a su propia finca privada. En la actualidad lleva en funcionamiento unos cuatro años en esta ubicación, operando con las nuevas técnicas para la obtención del mejor aceite de calidad. La almazara dispone de cuantos adelantos modernos se requieren en el molido de la materia prima, lavado, almacenamiento y obtención del aceite de un modo limpio y cuidado.

Además en el siguiente apartado, daré a conocer como se esta tratando el resultante de los desperdicios de la aceituna (su hueso molido y las hojas) para la obtención de un producto $100 \%$ ecológico, el resultante es un compuesto para el abonado de los campos. 
Con la construcción de la almazara fuera del casco urbano, este empresario quiso evitar las limitaciones para la entrada a su actividad que tenía en el pueblo puesto que los camiones de gran tonelaje no podían acceder a dicho lugar.

Con esto se consiguió:

- El poder comprar la materia prima desde cualquier parte en el caso de mala cosecha en esta zona y sin que ello suponga un elevado incremento en su precio.

- La eliminación del coste que supone el transporte intermedio para la venta del subproducto resultante en este proceso.

- La eliminación de todo tipo de mano de obra en proceso de trasiego de la aceituna.

Situación de la almazara:

El enclave de la almazara está centrado en una zona en la que ya no existe ninguna otra, diversificando la procedencia de su clientela entre los pueblos de Aguas, Altea, Benissa, Callosa D’En Sarria, Campello, Finestrat, La Vila, Orxeta, Relleu, Sella y en menor cantidad también hay clientela de Alicante, Benidorm, Benifato, Benimantell, Cocentaina, Confrides, Elche, L'Alfás del Pí, Torremanzanas, Polop, San Vicente y Jijona.

Características de la actividad:

La almazara cuenta con unos ochocientos clientes procedentes de veinte poblaciones circundantes a Relleu. La mayor fuente de ingresos de esta actividad viene de la prestación de servicios: Elaboración al oleicultor del aceite procedente de su propia cosecha y este trabajo supone una media de unos $150 €$ por cliente y campaña.

En todo el entorno (que es muy extenso) desde hace bastantes años ya no existe ninguna almazara que trabaje individualmente la cosecha de cada oleicultor, modalidad de trabajo conocida como maquila en términos almazareros. Las almazaras más cercanas son la de Agres y otra que también trabaja algo en este sentido es la de Millena. Las cooperativas ya hace años que han abandonado esta práctica, pues supone una infraestructura más específica y a su vez compleja: recepción, almacenamiento, elaboración, envasado y etiquetado totalmente individualizado de cada uno de los clientes.

En esta zona existe la arraigada costumbre de llevarse a casa el aceite de su propia cosecha y cada vez que sale algún tipo de escándalo alimentario por la televisión mas solicitada será la modalidad de maquila.

Es por estos dos motivos (la casi inexistencia de fábricas encaminadas a esta modalidad y la creciente tendencia de saber lo que uno come en casa) es por lo que estas nuevas instalaciones las ha seguido encaminando al trabajo tipo maquila. 


\section{Nuevas perspectivas}

Se da la circunstancia de que otra almazara que había por los alrededores concretamente en Muchamiel cerró en la campaña 2008, almazara que estaba molturando sobre el millón de kilos. En los meses posteriores fueron numerosas las llamadas telefónicas de oleicultores de este pueblo, los que llamaron para poder molturar su aceituna en Relleu y que después han ido incorporándose como clientes a esta almazara.

Por otra parte se supone un importante crecimiento de la producción de oliva en todos estos pueblos de los alrededores, pues posiblemente debido al último período de sequía que ha afectado mucho a los almendros, se han replantado todos estos términos con joven olivar, que muy pronto van a ir cosechando sus frutos.

También hay que considerar que desde la entrada en vigor del sistema de ayudas a la agricultura denominado paga única, se ha notado un importante incremento de oleicultores socios de la cooperativa de segundo grado de Muro de Alcoy que desean obtener el aceite de su propia cosecha.

Su finalidad va a ser la elaboración del aceite de oliva mediante métodos totalmente artesanales y que están por completo en desuso desde hace bastantes décadas. La intención es la de aportar a la actividad industrial de la almazara otra modalidad encaminada al turismo, asociaciones de amas de casa, colegios, etc.

\section{PLANTA DE COMPOSTAJE (ALPERUJO)}

El alperujo es el principal subproducto del actual sistema de dos fases de la industria almazarera. Los aprovechamientos principales del alperujo se centran en la extracción de aceite de orujo en las orujeras y en su aprovechamiento energético en las plantas de biomasa. Ambos aprovechamientos tienen en la actualidad algunos problemas ambientales y económicos. Una "novedosa" alternativa es el compostaje. El compostaje "en montones" se basa en reutilizar este subproducto como abono en el propio olivar, mediante una degradación bioquímica natural, con un sistema sencillo, el depósito en balsas apropiadamente acondicionadas para su evaporación inicial, posterior traslado a "eras de compostaje" en montones, la mezcla con hojín de la aventadora y estiércol adicional, su disposición en largas pilas, de 2 a 4 metros de altura, para su aireación por convección natural ayudada por volteos periódicos, controlando principalmente los parámetros de estabilidad, textura, humedad, temperatura, y relación CarbonoNitrógeno. Una vez compostado el producto, se procede al esparcimiento en el terreno, cerrando así el ciclo.

Las ventajas de este sistema son el secado rápido, porque se desprende humedad al voltear las pilas, el compostado resultante tiene menor humedad, la posibilidad de manejar un gran volumen de material, la buena estabilización del producto y la inversión relativamente baja. Los inconvenientes son el control de la aireación, es más difícil que con otros sistemas, puede producir malos olores especialmente durante los volteos, puede tener mal funcionamiento en condiciones climáticas lluviosas y requiere un mayor espacio para su ejecución. La disponibilidad del suficiente espacio y la 
posibilidad de producir algún mal olor ocasional, no son problemas para esta almazara, pues esta enclavada en el centro de una finca de unos 400.000 metros cuadrados.

El compostaje de alperujo puede ser para algunas almazaras una alternativa a su uso actual, viable medioambientalmente pero también económicamente, para esto es necesario hacer un análisis exhaustivo y comparativo del coste de ejecución y explotación de las instalaciones para el compostaje y del coste actual de deshacerse de este subproducto.

El alperujo puede tener interesantes usos o aplicaciones como: enmienda orgánica, puede controlar organismos fitopatógenos de los cultivos (efecto biopesticida) y puede mitigar los efectos adversos de plaguicidas y herbicidas en la agricultura, puede servir como complemento nutricional para rumiantes, puede servir como materia prima para la obtención de compuestos de alto interés biológico como el hidroxitirosol, o para la obtención de materiales interesantes eco-compatibles como el "woodceramics".

Objetivos fijados por la almazara de Relleu para el desarrollo de esta actividad:

a) El económico:

Reducir los altos costes resultantes del traslado del alperujo a las extractoras, pues la mas cercana esta en Albacete y al ser vehículos específicos para este tipo de mercancía, el kilometraje de la ida y vuelta ha de cargarse económicamente a un solo porte. Debido a esto y en el caso que nos ocupa de esta almazara salen costes de unos $0.03 €$ por kilo de alperujo que supone alrededor de un $20 \%$ del total de la facturación de la molturación de la oliva, según Jorge Font Cantó.

b) Los beneficios para el olivar:

Utilizar este compuesto de una manera natural y sostenible esparciéndolo en los mismos olivares de donde procede.

c) El desarrollo de la agricultura ecológica:

Los compuestos procedentes de la mezcla equilibrada de alperujos, biomasa y estiércoles, si su compostaje ha sido el adecuado, cumple con los requisitos actualmente en vigor para su uso en agricultura ecológica.

En estos dos últimos años se han dado de alta en el CAE alrededor de unas 500 hectáreas de cultivo ecológico sólo en el término de Relleu, según Jorge Font Cantó, que van a tener que comprar obligatoriamente abonos de tipo ecológico en muy corto plazo de tiempo y para la almazara son futuros clientes en la compra de este compostaje. 
d) La comercialización con los viveros de la zona:

Este compostaje de alta calidad, puede complementar o sustituir parcialmente a las turbas normalmente utilizadas en viveros. Es interesante hacer notar que estos substratos habitualmente empleados en los viveros, son recursos no renovables por proceder de las turberas. Así pues, abría que añadir al elevado coste de estos substratos debido a su transporte desde el norte, centro y este de Europa, el debate sobre la sostenibilidad de estos recursos. Se origina otro debate en el tema de la vinculación de la mayor parte de las turberas a humedales y al impacto que puede causar la explotación en el hábitat de la fauna migratoria asociada a esas áreas húmedas.

Elementos necesarios y consideraciones para la realización de dicha obra:

La producción actual de la almazara ya sobrepasa con creces los 500.000 kilogramos. Previendo un crecimiento de un $4 \%$ anual por introducción de la industria en nuevas zonas y otro $4 \%$ anual por entrada en producción de las nuevas plantaciones, la producción a ocho años vista será sobre 1.000.000 de kilos. La producción anual de alperujo a ocho años vista será de unos 800.000 kilogramos.

Balsa para el almacenaje de los lixiviados:

Se necesitan una balsa de almacenamiento con las siguientes dimensiones:
Ancho: $8 \mathrm{~m}$.
Largo: $12 \mathrm{~m}$.

Altura útil: $1.5 \mathrm{~m}$.

Capacidad Útil: $144 \mathrm{~m}^{3}$.

Altura total: $2 \mathrm{~m}$.

Capacidad Total: $192 \mathrm{~m}^{3}$.

Nota: Ambas balsas son aptas para el almacenamiento de agua de lavado de la oliva y/o lixiviados de la era de compostaje según las necesidades.

Era de compostaje (considerando dos turnos de trabajo):

Puesto que los montones de alperujo, con una considerable disminución del grado de humedad de este una vez transcurrido un tiempo, se pueden colocar en hileras, en forma de prismas triangulares, con dimensiones de unos cuatro metros de ancho por tres metros de alto, configurando una extensión de unos 1.000 metros cuadrados (por ejemplo 50 x 20 metros).

La era de compostaje debe contar con impermeabilización que permita conducir los lixiviados hasta un depósito igualmente impermeabilizado; en este caso se ha optado por una solera impermeable de hormigón armado.

Nave para el depósito del producto acabado o compostaje:

Se necesita una nave, o cubierta con cerramientos en al menos dos de sus lados, para almacenar el compostaje ya acabado, de unos 200 metros cuadrados (por ejemplo $10 \mathrm{x}$ 20 metros). 
Sistema de riego, para el control del grado de humedad del alperujo:

Se necesita sólo un sencillo sistema, para el riego del alperujo, cuando la temperatura aumente en exceso o el grado de humedad no sea el adecuado, que constará de una bomba y sistema de aspersores adecuadamente dimensionados.

Maquinaria necesaria:

Se necesita un tractor con pala para el traslado del alperujo y el compuesto, puesto que la almazara posee tractor, se considera sólo el coste de la pala.

Coste de personal:

Se necesita una persona durante el año, pero sólo para la manipulación inicial, y esporádicamente en las tareas de volteo, acopio, toma de datos (temperatura, grado de humedad y relación carbono/nitrógeno), riego y manejo en general del alperujo y el compostaje. Se estima que este trabajo puede desarrollarse semanalmente en 5 horas (estimaciones y presupuestos según proyecto).

Los datos de los cuadros 1 y 2 corresponden a las previsiones y costes aproximados sobre de la creación de esta actividad. Unos costes que el empresario Jorge Font Cantó, que es el dueño de la explotación, ha tenido que hacer frente ante la penosa situación económica que sufrimos a nivel nacional y mundial.

El hecho de que dicho empresario decidiese tomar esta iniciativa es muy elogiable pues si no fuese por este proyecto, los agricultores de la comarca tendríamos que trasladar nuestra producción de aceitunas a otras almazaras con el perjuicio que esto supone con los gastos de transporte y molestias que esto nos acarrearía.

Al mismo tiempo, esta planta de compostaje es un claro ejemplo del buen hacer de esta empresa por mejorar y fortalecer la agricultura ecológica, que a pesar que busca un beneficio privado como es lógico, debería percibir de algún tipo de ayuda económica por parte de la administración pues está hipotecando su futuro en una clara apuesta por mejorar las técnicas agrícolas y ecológicas de este entorno.

Dicho proyecto ya ha sido ejecutado y los frutos empezaran a cosecharse en los años próximos, pero mientras tanto, esta iniciativa le habrá dado muchos quebraderos de cabeza a su precursor, lo que desde aquí quiero recalcar que este empresario debería de haber tenido un poco más de apoyo por parte de la administración tanto central como comarcal. 
Cuadro 1. Inversión inicial según proyecto (en euros).

\begin{tabular}{|c|c|c|c|}
\hline Obra civil e instalaciones & Dimensiones (ud) & Precio unitario & Total \\
\hline m2 Desbroce y limpieza era & 1200 & 0,5 & 600 \\
\hline m2 Solera era compostaje & 1000 & 10 & 10000 \\
\hline $\mathrm{m} 2$ Balsa lixiviados & 192 & 39,5 & 7584 \\
\hline m2 Solera balsa lixiviados & 96 & 10 & 960 \\
\hline m3 Nave compost & 200 & 53 & 10600 \\
\hline $\mathrm{m} 2$ Sistema de riego & 1000 & 0,65 & 650 \\
\hline Honorarios & Base & $\%$ & Total \\
\hline Redacción proyecto técnico & 30394 & $16 \%$ & 4863,04 \\
\hline Material y equipos & $\mathrm{Ud}$ & Precio ud. & Total \\
\hline Pala cargadora & 1 & 4500 & 4500 \\
\hline Kg. Estiércol fresco inicial & 40000 & 0,03 & 1200 \\
\hline Permisos y licencias & Base & $\%$ & Total \\
\hline Estudio acústico & 1200 & 16 & 1392 \\
\hline Estudio ambiental & 2500 & 16 & 2900 \\
\hline Licencia municipal & 30394 & 4,8 & 1458,91 \\
\hline Total inversión inicial & & & 46707,95 \\
\hline
\end{tabular}

Fuente: Proyecto redactado para Jorge Font Cantó.

Cuadro 2. Costes y beneficios anuales (en euros).

Faena

Cantidad

Horas formación pilas

30

Precio unitario

Total

Horas volteos

50

25

750

Acopio y carga para la venta

30

25

1250

750

Producto

Compostaje producido y no

Cantidad

25

total

transportado

400000

Precio unidad

12000

Total transporte

$-12000$

Producto

Compostaje producido y no

transportado

Cantidad

Precio unidad

total

400000

0,03

12000

Total venta

12000

Fuente: Proyecto realizado para Jorge Font Cantó. 
El compost está compuesto por el hueso molido de la aceituna, las hojas de ésta triturada, estiércol de oveja y restos de poda también triturada.

Por su parte, el alperujo procedente de la almazara tiene un índice de un $40 \%$ de humedad. Tras unos meses ha perdido esta humedad y podrá ser transportado hasta la era de compostaje para la formación de las pilas dinámicas.

\section{LOS APROVECHAMIENTOS DEL RÍO AMADORIO}

\section{El sistema de riego a manta}

El término municipal es muy grande pues tiene 7.690 hectáreas (según el PGOU-2006), pero a pesar de ello tan solo un $15 \%$ son tierras de regadío a manta y a partir del año 2000 la superficie de riego a goteo se incrementó en un $10 \%$. Detallado el tipo de riego por partes:

El sistema de riego en Relleu hay que estructurarlo de la siguiente manera: existen cuatro azudes que son los encargados de regular el caudal del río y del riego. Estos azudes se encuentran situados en cada margen del río. Siendo el margen derecho el que tiene tres de estos azudes pero son de poca importancia y relevancia pues las tierras de regadío de dicho margen son menores. La importancia de este margen es que el agua de los sobrantes es la encargada de llenar la balsa de nueva creación. Cada uno de estos azudes se rige por sus propias normas o leyes, siendo estas diferentes del azud principal. En este margen la superficie en hectáreas puede rondar las 250.

El margen importante del río es izquierdo, que es el margen donde se encuentra situado el pueblo y por lo tanto donde más cerca esta de la población. Este azud esta institucionalizado por una comunidad de regantes denominada "comunidad de riego mayor" que consta de una junta directiva que es la encargada de las cuestiones jurídicas y administrativas de dicha comunidad. Bajo esta acequia se encuentran 450 hectáreas de tierra con derecho a riego. Los propietarios de las tierras situadas en este margen del río han de respetar las decisiones y atenerse a las normas que dicta dicha junta directiva. La junta cuenta con un presidente y unos vocales siendo el número de personas en la junta de ocho directivos (datos facilitados por José Daniel Senabre Soler, 2011).

Existe también la figura de un manaor del agua, que es la persona designada por la comunidad de regantes encargada de distribuir el agua del azud entre los propietarios que así lo deseen, cobrando por dicho servicio una cuota de $10 €$ la hora de riego más 10 $€$ si el riego lo realiza dicha persona.

En cuanto al sistema en sí, consta de una balsa de cemento ubicada en el curso alto del río, y que mediante una acequia recoge el agua del mismo y la conduce hasta la balsa. Una vez allí es distribuida por toda una red de acequias en su mayoría de tierra hacia los distintos bancales y terrenos de dicho azud. A la salida de dicha balsa, había ubicado uno de los numerosos molinos que existían en el pueblo para moler el trigo de la zona, este funcionaba gracias a la fuerza que ejercía el agua sobre sus poleas. Dichos molinos y la función que desempeñaban han desaparecido hace algún tiempo. 
El sistema de riego en estos azudes es el tradicional, el riego a manta. Un sistema, que en épocas de abundancia de agua y en regiones con superávit de este recurso, es muy codiciado pero que, en dicha zona donde el agua es muy escasa su desaprovechamiento es muy notorio. Además, al estar en un clima mediterráneo, donde los veranos son calurosos y secos, el río de característica irregular, experimenta un periodo de estiaje donde se seca por completo, con el perjuicio que eso acarrea a los cultivos pues durante unos días el agua es inexistente y estos están condenados a desaparecer.

En dicho entramado de acequias, también hay una serie de balsas de menor importancia aguas abajo del azud, que hacen la función de almacén y regulación del sistema, ya que la longitud del trayecto entre la cabecera del azud y las últimas tierras con derecho a riego puede oscilar alrededor de los 14 kilómetros. Hay que tener en cuenta que si se pretende regar las últimas tierras con derecho, para que el agua de la balsa mayor llegue hasta dichas tierras, el tiempo que transcurriría sería de unas 10 horas, algo que sería un malgasto muy evidente. Por eso se establece unas prioridades o riego por tandas, esto supone que las tierras van regándose de acuerdo a un orden jerárquico o latitudinal, pues se va regando desde las tierras más altas hasta las más bajas correlativamente, además de la regulación de las balsas de menor entidad e importancia.

\section{Tipos de cultivos en esta zona de regadío}

La mayor parte de estos cultivos son para el autoconsumo o la distribución o reparto a vecinos y amigos, siendo escasa y puntual la producción y posterior venta de algunos productos.

En cuanto a los tipos de cultivos de dicha zona, la gran mayoría son los cítricos, y dentro de estos el limón y en menor medida la naranja, ya que nos encontramos en una zona donde en invierno suele haber algunas heladas. También hay olivos y almendros dentro de las huertas, estos son mucho más desarrollados que el resto que hay esparcidos por término ya que son de secano. Este cultivo necesita menor cantidad de agua que los cítricos o los hortofrutícolas. También hay árboles frutales, eso sí solo para autoconsumo, como los nísperos, el caqui, la higuera o el granado entre otros.

En cuanto a los cultivos hortofrutícolas, estos están divididos en dos épocas y dos tipos de cultivo claramente diferenciados. En primer lugar se encontrarían los cultivos de invierno, como pueden ser los ajos, patatas y cebollas, así como las lechugas. Estos a excepción de las lechugas, se recogen los frutos a principios de verano y tienen la ventaja que las heladas y las inclemencias metereológicas no les afectan en gran medida.

El otro tipo de cultivo son los de verano, son cultivos que se plantan a mediados de primavera cuando las temperaturas ya se han suavizado. En este ámbito encontramos tomates, pimientos, berenjenas, sandias, melones, pepinos, etc., que viene a empezar su recolecta a principios de verano y que duran durante todo el mismo. Otro cultivo son los cardos o pencas que se limpian y se arreglan a finales de verano para que empiecen a producir de cara al otoño coincidiendo con la época de lluvias.

La mayoría de estos productos, como ya he reiterado con anterioridad, son para autoconsumo, a excepción de una explotación de nísperos que se encontraba ubicada en 
la parte baja del azud, pero que tuvo que realizar varios pozos y una gran balsa de riego, para garantizarse el agua durante todas las épocas del año. Dicha explotación ya no esta en funcionamiento debido a su poca rentabilidad en el mercado, ya este cultivo es muy delicado y necesita de numerosos cuidados. Además algunos años se veía afectado por algunas inclemencias metereológicas tales como el pedrisco, las heladas o la simple lluvia. En las zonas donde más se cultiva dicho producto (Callosa d'en Sarrià, Bolulla, Altea, etc.), se encuentra bajo plástico y muy protegido.

En estas parcelas también hay cultivos de vid para autoconsumo. Pero la triste regla que rige en todas estas parcelas es sin duda el abandono de las mismas. Cada vez se puede observar como gran cantidad de parcelas se encuentran abandonadas o en fase de abandono, sin que se proponga alguna solución al respecto. Esta pésima imagen paisajística de abandono afea a una muy degradada huerta de Relleu. Un pueblo que hasta no hace más de 30 años era agrícola y con suficientes recursos para sobrevivir aunque bien es verdad que con una agricultura basada en el secano.

\section{El sobrante del agua del azud y sus nuevos usos}

Para rentabilizar al máximo este recurso hídrico y aprovechar las crecidas del Amadorio y su caudal irregular, la Generalitat Valenciana mediante la cuenca hidrográfica del Júcar y gracias a unos fondos europeos, destinó una cantidad de dinero para la construcción de una gran balsa para que en épocas de superávit hídrico, con el agua que se perdía río abajo, se llenase la balsa destinada al riego moderno denominado riego por goteo. Esta actuación ha conseguido mejorar, ya que ahora es localizado, un $10 \%$ de las estas tierras de este azud (según los datos de la comunidad de regantes, 2011).

La balsa situada en el margen derecho del río ha mejorado las 70 hectáreas de superficie bajo acequia con capacidad de riego. En su mayoría este goteo es para almendros y olivos para mejorar su productividad y rentabilidad. También se cultivan productos hortofrutícolas ya que gracias a las dimensiones de la balsa el agua esta garantizada durante la época estival.

Otra infraestructura que se esta desarrollando es la construcción de una nueva balsa de riego, y toda la red de tuberías esparcidas por la zona de la huerta para abastecer la demanda que podría surgir en la zona. Las obras se encuentran muy avanzadas con la mitad del proyecto ya ejecutado y con el propósito de ponerla en circulación cuanto antes. En la actualidad se podría estar llenando, ya que el Amadorio mantiene un caudal bastante regular y el agua se esta perdiendo por dicho transcurso. Esta infraestructura también esta subvencionada por fondos europeos que a través de la Generalitat y mediante la cuenca hidrográfica del Júcar con un desembolso de 8 millones de euros (según los datos de la comunidad de regantes, 2011).

\section{Algunos legados, infraestructuras y costumbres de nuestros antepasados}

Este sistema de riego y la manera de trabajar la tierra es la que en su día pusieron en práctica los romanos en primer lugar y después los árabes. De los romanos nos llega alguna construcción denominada arcà, que se trata de una réplica a pequeña escala del acueducto de Segovia, con la misma función, canalizar el agua de un lugar a otro 
salvando un desnivel del terreno. También existe otra construcción de época de medieval, según informa José Daniel Senabre (2011). Con este fin también se crearon en épocas posteriores los denominados sifons, (sifones en castellano). Además, los árabes ampliaron toda la canalización de las aguas e introdujeron diferentes cultivos.

\section{ACTIVIDADES EN DESUSO}

Durante muchos años todas las actividades que se citan a continuación servían como fuente de ingresos suficiente para las personas que las desarrollaban. Actividades como podadores, artesanos de la piedra, eran trabajos que requerían de sabiduría y experiencia para desarrollarlos y que en la actualidad apenas se desarrollan por los vecinos de este municipio. El único que aún es necesario es el de podador, aunque también es cierto que durante el siglo XX existían varias cuadrillas de estos profesionales y en la actualidad solo se dedican tres personas y a tiempo parcial (temporeros). La mayoría de los agricultores son ellos mismos los que se limpian sus árboles, no porque entiendan en exceso, sino porque si pagan a estos profesionales al cabo del fin del año, no les queda ningún beneficio de la explotación. Esta profesión durante los años ha ido pasando de padres a hijos, que al criarse en estas circunstancias, adquirían conocimientos y experiencias que al fin y al cabo son las principales para desarrollar esta actividad.

En cuanto a los artesanos de la piedra ocurre lo mismo, eran trabajos necesarios para aterrazar los bancales, y que durante los años en los que la agricultura era la actividad principal de la población, eran imprescindibles. Al dar una vuelta por este entorno, surgen multitud de bancales ya abandonados que fueron aterrazados durante el siglo XIX y que todavía conservan los márgenes de piedra. Constituyen verdaderas obras de ingeniería que siguen inalterables con el paso de los años. En cambio en la actualidad, en este municipio no existe ningún profesional que se dedique a dicha labor, si se esta construyendo alguna obra de estas se ha tenido que buscar a gente de otros pueblos para realizar dichos trabajos, que en ningún caso son para arreglar los bancales de las explotaciones, sino que son márgenes cerca de las casas para decorar. Además el sistema no es ni parecido al de la antigüedad existen claras diferencias. Ahora se utiliza el cemento y un tipo de piedra que se rompe y se carea con facilidad, además de la posibilidad de movilizarla a cualquier lugar sin que esto suponga ningún esfuerzo. Antes esto era impensable e inviable, en primer lugar porque la piedra era la que había en cada lugar, si estabas cerca del río eran cantos rodados y si no se aprovechaba la piedra que había más a mano. En segundo lugar la movilidad era mediante fuerza animal o a lo sumo con tractores y en tercer lugar porque en el verdadero arte de amaestrar la piedra seca no se utiliza el cemento, la piedra se arregla con tierra y los clastos de las mismas. Los agricultores locales, cuando se nos cae algún margen, intentamos reconstruirlo con nuestros medios o bien rellenar el hueco con tierra, con tal de evitar llamar a estos profesionales ya que suelen cobrar entorno a los $60 €$ el metro cuadrado de margen construido.

Otras actividades agrarias ya extinguidas son los artesanos del esparto y los fabricadores de la cal y el carbón vegetal. Por estos parajes las esparteras forman parte natural del paisaje, dando a entender así que en tiempos atrás este recurso natural era utilizado por estos habitantes. Tanto es así que múltiples utensilios cotidianos están elaborados con este material. Algunos ejemplos de utilización de este material son las suelas de las alpargatas campesinas, el aventador para el fuego, utensilios para colocar las cazuelas y 
las paellas en mesa evitando así que se queme el tapete, caracoleras, etc. También se utilizaba en la agricultura concretamente para la fabricación de capazos y cestas, o para atar las tomateras a las cañas, entre otros usos. El modo de obtención de este recurso natural era algo trabajoso y requería de mucha mano de obra, ya que se debía extraer el esparto del monte en primer lugar. Una vez cosechado se colocaba tendido al sol para que se secara, evitando que la lluvia lo mojase. Normalmente se realizaba en verano para evitar dicha inclemencia metereológica. Una vez secado, se recogía y se picaba con el fin de dejarlo como el hilo, fino y flexible para después poder trabajarlo con facilidad. En la actualidad estas labores se hacen mecánicamente y a pesar de ello, los utensilios obtenidos con este material alcanzan un precio elevado en el mercado.

Otras actividades en desuso desde hace décadas son las que conciernen a la fabricación cal y carbón mediante métodos tradicionales y yo diría artesanales. Para los dos se requiere de una cantidad de masa forestal abundante por los alrededores, puesto que para la obtención de estos materiales, se debe de quemar gran cantidad de leña. En la fabricación de cal el mecanismo es el siguiente, según las ideas aportadas por José Signes Ibáñez (2010): en primer lugar se prepara un hoyo, lo que será en un futuro una especie de semicírculo de tierra con una sola entrada por un lateral y una altura que dependerá de la agrandaría que se le quiera dar. Seguidamente se colocan una serie de piedras calizas formando un horno, dejando por debajo el hueco suficiente para la colocación de la leña, que deberá arder durante al menos 72 horas. Dicha cúpula de rocas se tapa con tierra dejando una chimenea en su cima, por la cual este horno consigue respirar, (dicha chimenea permite la entrada de oxígeno que permite la combustión de la leña que existe en el interior). Una vez transcurridas las 72 horas, las piedras calizas ya se han fundido y transformado en cal. En la década de los años sesenta, el kilo de cal oscilaba entorno a 1 peseta, precio que aunque parezca ridículo ahora en aquella época era dinero, según indica Dolores Climent Font (2010). La cal tenía múltiples aplicaciones tanto para la pintura como para tratar el agua o para abono para la tierra.

En cuanto al carbón este se realizaba de una forma parecida. Aquí lo que se quema y se aprovecha es la leña. Esta se apila formando un montón (tan grande como se quiera) y se cubre con tierra dejando una chimenea en la cima y un pequeño orificio en un lateral para que exista una circulación de oxígeno y pueda prender con facilidad. Una vez prendida, se tapan los orificios para que no entre oxígeno y conseguir así que el fuego se ahogue. Como no existe circulación del viento el fuego termina por apagarse obteniendo así este recurso natural que es el carbón. En Relleu existían cuadrillas que se dedicaban a realizar estas carboneras durante todo el año, en parajes como el Cabeçó, la Grana o la sierra del pantano. En la actualidad esta labor esta totalmente en desuso.

Otra actividad tradicional que esta desapareciendo es la ganadería. Si en la década de los años sesenta existían unas 3.000 cabezas de ganado ovino y caprino pastando en nuestro término, ahora en la actualidad esta cifra se ha reducido a 400 cabezas. De las cuales 270 están estabuladas o salen poco a pastar, y repartidas entre numerosos agricultores, que fieles a un pasado pastoril, mantiene unas cabezas de ganado por amor propio y recurso de alimento, pues los corderos son sacrificados para autoconsumo. El resto forman parte de un ganado antiguo que conserva la cartilla ganadera. Y es que para la obtención de la cartilla ganadera se necesitan varios requisitos que los ganaderos actuales no están dispuestos a cumplir, ya que este tipo de ganadería no interesa y no es rentable en la actual Europa, se exigen muchas condiciones para llevarla a cabo. 
Además, el precio de la carne en el mercado es bajo y las ayudas económicas a este tipo de ganadería son nulas o insuficientes. Se perderá así una profesión en esta zona que, no solo es capaz de abastecer el mercado de carne local o comarcal, sino que desempeñan la labor de limpieza de montes y bancales. Evitando así, que la vegetación tan abundante, no sea el motor de combustión de los incendios forestales. Es algo que Europa tendría que reconsiderar o al menos analizar. (Gómez Manzanares, 1967).

Otra cabaña abundante que existía con fines de autoconsumo era la porcina, la mayoría de las masías dedicaban un espacio para la cría del cerdo o de los cerdos, si la casa era grande. Se mataba el animal y se realizaba el embutido o se sazonaban ciertas partes con el fin de comer dicha carne durante la mayor parte del año. En la actualidad esta práctica se ha reducido bastante, hasta el punto que son pocas las casas que practican esta costumbre tradicional y las que lo llevan a cabo es para juntar a la familia durante unos días. En esta zona no se criaban los cerdos para venderlos como en otras partes de la provincia de Alicante. Aquí era para autoconsumo. (Martín, 1996).

En cuanto a las aves esas si son más abundantes y con mayor representación. En casi todas las masías existen algunas aves como gallinas, pollos, palomas y el tipo de aprovechamiento es el tradicional, autoconsumo o autoabastecimiento. No existen granjas, por lo tanto no existe la venta al mercado.

\section{CONCLUSIONES}

Los habitantes de este pueblo vivimos en un entorno privilegiado de la costa blanca, cerca de la playa (a 20 kilómetros), del bullicio de la gente en la costa, de los lugares de trabajo en las ciudades, de este sol radiante que tenemos durante más de 300 días al año y que nos da esta alegría de vivir que existe por estas zona. Además si lo que queremos es tranquilidad este es un lugar tranquilo, entrañable, donde se palpa la naturaleza y su grandiosidad por los cuatro costados. En cambio, si lo que queremos es trabajar aquí viviendo de la agricultura como lo hicieron nuestros antepasados, la cosa cambia. Este tipo de agricultura de secano y familiar, se ha quedado obsoleta, anticuada, arcaica puesto que no es rentable, ni sostenible. Esta cantidad de bancales estrechos, cortos, con poco margen de maniobra, no son muy idóneos para mecanizarlos y que para la hora de trabajar en ellos es difícil y engorroso. Además, la superficie de las explotaciones se va reduciendo con el paso de las generaciones, las herencias familiares pasan de padres a hijos y se van dividiendo las parcelas según el número de miembros de la familia. Esto hace que las parcelas sean más numerosas y además de menor tamaño.

Además, otro factor que hace de esta agricultura insostenible es el elevado precio de los carburantes, un precio que solo hace que incrementarse. En los últimos años ha pasado de los noventa y cinco céntimos del año 2006 al euro y veinticinco de este mes de junio. Bien es cierto que existe un gasoil bonificado (denominado tipo B) pero que solo puede ser comprado por agricultores profesionales, lo cual hace que un propietario de una pequeña explotación no pueda acceder a él (Escudero, 1996).

Otro factor es el precio que se recibe por las cosechas, un precio irrisorio en muchas ocasiones que hace que el agricultor se plantee la opción de arrogar sus productos otra vez al campo o dejarlos perder en el árbol para así, al menos, no tener que trabajar a la 
hora de cosecharlos. Lo único que consiguen con estas políticas es que se abandone el campo, que por otra parte es lo que se persigue por parte de la PAC (Giddens, 2001).

Para intentar encauzar de nuevo este tipo de agricultura familiar en esta zona se podrían realizar una serie de actuaciones que ayuden o por lo menos intenten iniciar un camino a seguir para dinamizar y realzar la economía de este sector y para que éste entorno no se degrade. También para que no se abandonen más cultivos y hectáreas del término municipal y para que quede una herencia para nuestros progenitores de un tipo de vida saludable y una agricultura sostenible. En entre estas actuaciones se encuentra el cooperativismo local, para la compra y utilización de la maquinaria (herramientas), para compra de gasóleo en grandes cantidades para que sea más económico, así como a la hora de pedir subvenciones o ayudas por medio de créditos que se tenga más respaldo a través de ésta institución. Otra actuación es la creación de una marca de calidad, una marca ecológica, crear un nombre para nuestros productos ecológicos, promocionar el aceite y la almendra, la huerta, para que a la hora de venderla el precio sea un poco más elevado (algunos lugares de la provincia lo han conseguido por ejemplo las cerezas de la montaña, la uva del Vinalopó, el níspero de callosa, etc.). Promocionar otros recursos complementarios a la agricultura como la artesanía, enfocada al desarrollo turístico rural (no urbanístico), mediante por ejemplo las siguientes actuaciones: utensilios de esparto (tan abundante en esta zona), visitas guiadas para dar a conocer como se extrae la cal, el carbón o como se construye un margen de piedra seca (ya no simplemente para darlo a conocer sino para atraer a posibles clientes). Introducir y cambiar a otros tipos de cultivos que sean más rentables, así como cuidar la ganadería (fabricando y vendiendo quesos, por ejemplo).

Sea como fuese desde aquí quiero hacer hincapié en comenzar a reactivar este sector, esta zona de la provincia de Alicante que ha vivido siempre durante mucho tiempo de lo que daba el terreno y que ahora el terreno solo da que disgustos y pérdidas. Si se tiene que cambiar el tipo de cultivo, lo cambiaremos, si nos tenemos que amoldar a lo que nos digan desde Bruselas, nos amoldaremos (hablo en nombre de los habitantes de Relleu), con el fin de poder continuar viviendo en esta zona y de esta actividad que se viene desarrollando desde que se introdujera en el Neolítico.

\section{BIBLIOGRAFÍA.}

BOVÉ, J. ¿Una internacional de agricultores? New Left Review, 2002, nº 12, p. 128-139.

CLAIRMONT, F. F. Doscientas sociedades controlan el mundo. Le Monde Diplomatique (edición española), 1997, abril, p.8-9.

Consejo Oleícola Internacional. Catálogo Mundial de Variedades de Olivo. Madrid, 2000.

ESCUDERO, G. Problemas e implicaciones de nuevos modelos de desarrollo para la agricultura, la alimentación, el medio ambiente y la pobreza rural. San José, (Costa Rica): IICA, 1996.

GIDDENS, A. Un mundo desbocado. Los efectos de la globalización en nuestras vidas. Madrid: Taurus, 2001. 
GÓMEZ MANZANARES, R. La ganadería, la empresa ganadera y el informe del Banco Mundial y de la FAO. Información Comercial Española, 1967, n 403, p. 95101.

HO, M.-W. El inevitable retorno a una agricultura sana. The Ecologist (edición española especial), 1998, vol. 28, nº 5, p. 66.

HOBBELINK, H. (Ed.). Más allá de la revolución verde. Las nuevas tecnologías genéticas para la agricultura. ¿Desafio o desastre? Barcelona: Lerna, 1987.

JUAN y FENOLLAR, R. La información de la agroindustria en España, 1960-1970. Madrid: Ministerio de Agricultura, Pesca y Alimentación, 1978.

LÓPEZ, J. Tierra sin hombres y hombres sin tierra. Mate amargo, 1997, nº 107, p. 2-4.

MARTÍN MARTÍN, V. O. La geografía, la Unión Europea y el desarrollo rural. VIII Coloquio de Geografía Rural. Jaca, 1996, p. 237-249.

Ministerio de Agricultura, Pesca y Alimentación. Hechos y cifras del sector agroalimentario español. Madrid, 2000.

SÁNCHEZ, J. E. La geografía y el espacio social del poder. Barcelona: Los Libros de la Frontera, 1981.

SEGRELLES SERRANO, J. A. Agricultura y territorio en el MERCOSUR. Alicante: Publicaciones de la Universidad de Alicante, 2003.

VELARDE FUERTES, J. (1967). La ganadería española, ¿iluminada por el Informe Banco Mundial-FAO. Información Comercial Española, 1967, nº 403, p. 85-94.

VIERI, S. La política agrícola comune. Dal trattato di Roma alla Riforma Mac Sharry. Bologna: Edagricole, 1994.

\section{RECURSOS ELECTRÓNICOS UTILIZADOS}

- http://www.sabormediterraneo.com

- http://www.fruitveg.com

- http://www.llotjadereus.org

\section{AGRADECIMIENTOS}

Los primeros agradecimientos son para mi familia en especial para mi padre José Climent Font, que es el que más me ha enseñado las labores y quehaceres del campo así como los entresijos de éste. También son de agradecer los comentarios de otra parte de mi familia como es mi tía Dolores Climent (Lola) y mi tío Pepe Signes que me 
indicaron como elaboraban y vendían la cal y el carbón allá por los años 60. Otros comentarios y reflexiones en este caso de amigos son los de José Daniel Senabre Soler que era profesor de Historia ya que se jubilo en el presente año. Senabre Soler es además directivo de la cooperativa de Relleu y de la comunidad de regantes. También y para los datos concretos del PGOU y del censo así como de alguna fotografía debo mis agradecimientos a mí amigo Juan José Pérez Santonja y a su novia Patricia.

Agradezco también la ayuda y el saber de algunos profesores de la universidad de Alicante entre ellos a Pablo Giménez Font, Felipe Sigüenza Tari; así a José Antonio Segrelles Serrano.

Además, también es de agradecer la ayuda de Tomás y Pilar Llinares Serra y de Antonio Seva Carbonell que cuando les di a conocer mi propuesta sobre la realización de este articulo me ofrecieron el catálogo mundial de las variedades de olivo. Libro con el cual he realizado el apartado de la aceituna.

Otra pieza fundamental de este articulo y que no dudo en ayudarme fue el propietario y empresario de la almazara Jorge Font Cantó que me facilitó muchos datos y fotografías para la realización de este articulo, gracias de verdad Jordi.

Además y para terminar dos personas que me han ayudado con el resumen en inglés que son Ben James y Emma Sánchez. 